Political Skill Camouflages Machiavellianism: Career Role Performance and Organizational Misbehavior at Short and Long Tenure

Gerhard Blickle*, Bastian Kückelhaus*, Iris Kranefeld*, Nora Schütte*, Hanna A. Genau*, Dominic-Nicolas Gansen-Ammann† \& Andreas Wihler:

* University of Bonn, Germany

$\dagger$ Hochschule Fresenius Köln, Germany

† Frankfurt School of Finance \& Management, Germany

Accepted for publication (2020-02-12) by

\title{
Journal of Vocational Behavior
}

This manuscript does not exactly replicate the final version to be published in the Journal of Vocational Behavior. It is not the copy of record.

Accepted for publication 2020-02-12

Corresponding author: Gerhard Blickle, Arbeits-, Organisations- und

Wirtschaftspsychologie, Institut für Psychologie, University Bonn, Kaiser-Karl-Ring 9, 53111

Bonn, Germany, Fon: +49 228 734375, Fax: +49 228734670.

E-mail: gerhard.blickle@,uni-bonn.de 


\section{Highlights for review}

- We jointly tested socioanalytic and mimicry deception theory

- We predicted career role performance and counterproductive work behavior

- We used a two-study triangular research design with 1,438 study participants

- Political skill masked Machiavellianism as predicted by socioanalytic theory

- Mimicry deception theory was only partially supported by the data 


\begin{abstract}
On the basis of socioanalytic theory (Hogan \& Shelton, 1998) and mimicry-deception theory (Jones, 2014), we hypothesized that political skill would effectively mask Machiavellianism (socioanalytic theory) with consequences for coworker perceived career role performance and actual counterproductive work behavior at low and high levels of job tenure (mimicrydeception theory). We tested our hypotheses in a triangular multisource design in two complementary studies comprised of both target workers and coworkers with a total of $N=$ 1,438 participants. In Study 1, we found that when political skill was high, targets received high career role performance ratings from coworkers, and this was also the case when targets had high levels of Machiavellianism (socioanalytic masking effect). For targets with low political skill, the career role performance ratings of high Machiavellians was low at long tenure. The results of Study 2 partly disconfirmed mimicry-deception theory: Individuals high in Machiavellianism and high in political skill did not tend to avoid engaging in overtly mean behaviors toward others and extracting organizational resources at short tenure. Implications and limitations are discussed.
\end{abstract}

Keywords: Machiavellian personality, socioanalytic theory, mimicry-deception theory, political skill, career role performance, counterproductive work behavior 
Political Skill Camouflages Machiavellianism: Career Role Performance and Organizational Misbehavior at Short and Long Tenure

Interest in research on vocational behavior from the dark side has been increasing (for a review, see Hirschfeld \& Van Scotter, 2019). Such research addresses not only dark traits but also values, motivations, self-concepts, and interests, which are not inherently dark (e.g., a preference for power) but pose risks to the people who endorse them as well as risks to others (e.g., career derailment; Hogan, Hogan, \& Kaiser, 2011). Hogan and Shelton (1998) highlighted selfishness, treachery, and deceit in these dark trait dispositions and claimed that they can coexist with good social skill. Hirschfeld and Van Scotter (2019) identified vocational research on six dark traits: social dominance orientation, psychological entitlement, dispositional greed, and the dark triad traits. The dark triad traits (i.e., psychopathy, narcissism, and Machiavellianism; Paulhus \& Williams, 2002) tend to manifest in a socially malevolent character with behavioral tendencies that lean toward self-promotion, emotional coldness, duplicity, and aggressiveness. These interpersonally directed aspirations and intentions are fueled by the motive to get ahead (i.e., achieve vocational adjustment) at the expense of others.

Socioanalytic personality theory has strong implications not only for vocational choice (Hogan \& Blake, 1999) but also for vocational adjustment because it holds that social skill helps not only bright but also dark personalities improve their career success (Hogan \& Blickle, 2018). As Hogan and Shelton (1998) described, "social skill concerns translating these interpersonal aspirations into action; social skill allows one to achieve his or her interpersonal goals just as hand-eye coordination allows one to hit a tennis ball accurately" (p. 135). Recent research has supported this hypothesis for two dark triad personality traits: narcissism (Owens, Wallace, \& Waldman, 2015) and psychopathy (Schütte et al., 2018). In the present study, we focused on the third trait of the dark personality triad: Machiavellianism (MACH). This construct was originally developed as a personality trait by Christie and Geis 
(1970) on the basis of a selection of statements from the political theory by Niccolò Machiavelli (1950), an Italian diplomat, politician, and writer of the Renaissance period. He argued that politics is amoral and that any means, however unscrupulous, is normal and effective for achieving and retaining political power. At the same time, politicians need to create a positive reputation to be effective. Indeed, biographical analyses have identified trait MACH in well-known political figures such as John F. Kennedy, Mahatma Gandhi, Fidel Castro, and many other politicians (Bedell, Hunter, Angie, \& Vert, 2006).

Apart from these prominent examples in international politics, MACHs can also be found in the workplace (Dahling, Whitaker, \& Levy, 2009) because political perspectives also apply to organizations and careers, and organizational settings are often the contexts in which MACHs enact vocational behavior (Ferris, Harris, Russell, \& Maher, 2018). MACHs strive for promotions to positions of control and personal gain, and they exploit their credibility in positions of trust for personal gain (Hirschfeld \& Van Scotter, 2019). However, not all MACHs are successful in achieving vocational adjustment. Our research addresses this gap in the literature (Hirschfeld \& Van Scotter, 2019) by focusing on political skill as a moderating condition.

Viewed through the lens of politics, vocational careers can be seen as political campaigns (Inkson, 2004) that involve self-promotion, impression management, and the use of influence tactics (Bing, Davison, Minor, Novicevic, \& Frink, 2011). In career research, it has become clear that some individuals are more successful at managing the political landscape than others, namely those with high social skill at work (i.e., political skill; Ng, Eby, Sorensen, \& Feldman, 2005). This emerging individual difference construct (Ferris et al., 2005) was designed to capture the social savvy and competencies an individual needs to effectively achieve organizational and/or personal career goals. Political skill is related to other social effectiveness constructs (i.e., leadership self-efficacy, self-monitoring, emotional intelligence) while still providing a superior contribution to criterion validity (Semadar, 
Robins, \& Ferris, 2006). In recent years, several meta-analyses have successfully demonstrated the reliability, generalization, and construct and criterion validity of the political skill construct at work and in careers (Bing et al., 2011; Jacobson \& Viswesvaran, 2017; Munyon, Summers, Thompson, \& Ferris, 2015; Ng et al., 2005).

For psychopathy, political skill engenders the sustainable upside of this trait in organizations (Schütte et al., 2018). However, for MACH, we argue that political skill creates a protective façade for the long-term successful enactment of its dark core in the workplace. This can be subsumed under the construct of counterproductive work behavior (CWB; Bennett \& Robinson, 2000). Counterproductive work behavior is voluntary behavior that violates legitimate organizational interests and norms, and in doing so, threatens the wellbeing of the organization (CWB-O), its members (CWB-I), or both (Bennett \& Robinson, 2000). Building on mimicry-deception theory (Jones, 2014), which focuses on how MACHs use organizational settings as the context in which they enact vocational behavior, we suggest that some individuals high in MACH use a complex, long-term deceptive strategy: In an initial stage, they create a positive image in order to become well-integrated into the organization. Subsequently, at a later stage, interpersonal harm and organizational misbehavior follow, entailing high levels of CWB. However, the dose of CWB in the long run remains at such a well-calculated level that the positive evaluation of these individuals by coworkers concerning career role performance (Welbourne, Johanson, \& Erez, 1998) is not jeopardized. Thus, if the protective façade of the wrongdoers is effective, what coworkers see is not what MACHs actually do in the long run.

Our research addresses the following gaps in the pertinent literatures. First, the empirical testing of mimicry-deception theory (Jones, 2014) is still in a nascent state, especially with reference to its vocational career implications. We elaborate and empirically test its implications for vocational careers. Whereas Templer (2018) recently suggested that, akin to mimicry-deception theory (Jones, 2014), dark personalities get ahead via reputation 
building, Templer tested only the camouflage hypothesis with reference to task and team performance. Looking through the lens of vocational career politics (Inkson, 2004), the next important step is to analyze the reputation for successful career behavior as an important driver of career success (Blickle, Schneider, Liu, \& Ferris, 2011).

While climbing the organizational ladder, dark personalities create a multiplicity of negative consequences (O’Boyle, Forsyth, Banks, \& McDaniel, 2012; Van Vugt, Hogan, \& Kaiser, 2008). Therefore, our second contribution is to foster a deeper understanding of the mechanisms that help individuals high in MACH successfully camouflage their counterproductive work behaviors in their vocational careers. Previous research has already shown that political skill can mask deviant workplace behavior to hide it from unsuspecting coworkers, thereby creating a protective façade for the wrongdoer. Treadway, Shaughnessy, Breland, Yang, and Reeves (2013) found that workplace bullies with high levels of political skill were able to abuse coworkers and still receive high ratings of performance from their superiors. Likewise, even for leaders engaging in deviant leader behavior (Mackey, McAllister, Maher, \& Wang, 2019), in a leadership study of midlevel managers, Harvey, Harris, Kacmar, Buckless, and Pescosolido (2014) found that when managers exhibited a high degree of political skill, employee perceptions of ethical leadership increased. However, the specific career implications of the deviant behaviors of dark personalities have not yet been empirically tested with reference to the combination of $\mathrm{MACH}$, political skill, and tenure (Hirschfeld \& Van Scotter, 2019). By investigating the moderating role of political skill in the relation between $\mathrm{MACH}$ and both reputation for career role performance and $\mathrm{CWB}$, we aim to unveil how MACHs might successfully camouflage their wrongdoing and get ahead in their vocational careers.

Regarding dark personalities, we often observe two virtually separate lines of research: studies on criminal offenders on the one hand and studies on dark personality at work on the other hand. Therefore, our third aim is to close this gap by including behaviors at extreme 
levels of MACH. A recent study of adult criminal offenders found a convex pattern of curvilinear relations between emotional coldness, which is an important feature of MACH (Paulhus \& Williams, 2002), and antisocial behaviors, indicating an increased likelihood of antisocial behaviors at extreme levels of emotional coldness (Weiss et al., 2019). We extended the findings from this study by analyzing the patterns of curvilinear relations between MACH and CWB (Bennett \& Robinson, 2000) at extreme levels of MACH.

In conclusion, research in the area of dark personalities, organizational politics, and vocational careers has called for a greater understanding of how dark personalities and politically skilled individuals operate (Ferris, Ellen, McAllister, \& Maher, 2019; Jones, 2014; Templer, 2018), and this paper addresses pertinent gaps by probing the short- and long-term strategies enacted by a particular type of dark personality (i.e., MACHs), the reputational consequences, and behavioral manifestations.

\section{Theoretical Foundations}

\section{Socioanalytic Theory, MACH, and Political Skill}

Socioanalytic theory holds that human nature is rooted in biological evolution. People are motivated by a specific combination of two social motives: a need for status, power, and the control of resources, and a need for community, approval, and acceptance. These needs are referred to as the motive to get ahead and the motive to get along (Hogan \& Blickle, 2018). In individuals high in $\mathrm{MACH}$, whereas the motive to get ahead is high, the need to get along is low as O’Boyle et al. (2012) argue from a social exchange perspective (Blau, 1964): Individuals high in $\mathrm{MACH}$ tend to have a purely instrumental relationship with others. They get in contact with others not because they intrinsically desire or enjoy meeting other people but to tap other people for information the MACHs can use for their benefit. They are prepared to sabotage the efforts of others if they perceive such others as threatening their own ability to gain status and power (Dahling et al., 2009). In order to manipulate others for the 
sake of their own benefit, they often use deceptive impression management tactics (DePaulo \& Rosenthal, 1979).

Specifically, MACH is a personality trait that characterizes individuals with distrustful and cynical views of human nature (Christie \& Geis, 1970). They seek wealth, power, and status, they desire control over other people, and they selectively manipulate and betray others when the opportunity for gain is present (Dahling et al., 2009). In the workplace, MACH has been associated with unethical intentions and behaviors at work (Kish-Gephart, Harrison, \& Trevino, 2010), lower job performance, and higher counterproductive work behavior (CWB; e.g., theft, fraud, defection, bullying; O’Boyle et al., 2012), abusive supervision (i.e., sustained display of hostile verbal and nonverbal behaviors toward subordinates; Greenbaum, Mawritz, \& Quade, 2017), reduced willingness to share knowledge (Liu, 2008), and knowledge hiding (Pan, Zhou, \& Zhang, 2016).

According to socioanalytic theory, differences exist in both the strength and extent to which individuals possess the motives to get ahead or get along as well as individuals' abilities to pursue these motives (Hogan \& Shelton, 1998). In essence, these motives reflect individuals' interpersonal aspirations (i.e., what one aspires to do; Hogan \& Shelton, 1998). However, not everyone who aspires to get along or get ahead is equally equipped to do so. Accordingly, whether individuals are successful at pursuing either or both of these basic motives will depend on their social skill.

Social skill refers to individual differences in how one goes about pursuing their motives. As such, individuals who are socially skilled are more capable of translating their basic motives (i.e., their aspirations) into purposeful and, more importantly, successful action (Hogan \& Shelton, 1998). Given the widespread evidence establishing a certain kind of social skill, that is, political skill, as an important workplace-specific social competency (e.g., Blickle, Frieder, \& Ferris, 2018; Munyon et al., 2015) in relation to socioanalytic theory 
(Hogan \& Blickle, 2018), MACHs with political skill are capable of transforming a desire to get ahead into social success.

As a whole, political skill is a comprehensive blend of social competencies reflecting "the ability to effectively understand others at work and to use such knowledge to influence others to act in ways that enhance one's personal and/or organizational objectives" (Ferris et al., 2005, p. 127). Political skill comprises four key facets (Ferris et al., 2005, 2007, 2008). First, social astuteness refers to sensing the motivations and agendas of others. Second, interpersonal influence comprises the capacity to persuasively communicate with others. Third, networking ability captures the building, fostering, and use of interpersonal relationships and connections to achieve work- and career-related goals. Fourth, apparent sincerity entails conveying authenticity while influencing others at work.

Especially with reference to reputation building and masking malevolent social behavior at work, we suggest that the social astuteness and networking ability dimensions of political skill are critical in the opportunity recognition stage of social influence, whereas the interpersonal influence and apparent sincerity facets are critical in the opportunity capitalization stage of social influence (McAllister, Ellen, \& Ferris, 2018). Researchers have argued that, as a function of their acute understanding of others as well as the intricacies of social interactions, their uncanny ability to appear sincere and trustworthy, and their unmatched behavioral versatility, politically skilled individuals are thought to recognize opportunities and appropriately package or disguise their motives (to [not] get along or get ahead) in ways that are well-received by others (Blickle et al., 2018).

As such, individuals high in $\mathrm{MACH}$ and in possession of political skill should be more capable of designing and employing complex strategies to build trust, confidence, and a good reputation among coworkers to gain access to organizational resources. And, indeed, previous research has found that political skill can mask CWB from unsuspecting others, thereby creating a protective façade for the wrongdoers (Harvey et al., 2014; Treadway et al, 2013). 
Without political skill, however, it is likely that individuals high in MACH will engage openly in CWB and this will be followed by career derailment (Hogan et al., 2011), whereas success in getting ahead in organizations is fostered by a reputation for career role performance (Welbourne et al., 1998).

\section{Reputation for Career Role Performance}

Organizational career management is aimed at recruiting new employees, assessing and improving employee performance, fostering employees' organizational commitment, and helping employees develop skills to meet their future career needs. In today's organizations, employers and employees share the responsibility for career management (Wiernik \& Wille, 2018). Career role performance refers to how well employees progress in their career roles, seek out career opportunities, develop skills needed for future career steps, and attain personal career goals (Welbourne et al., 1998).

Socioanalytic theory holds that coworkers continuously exchange views on how easy it is to deal with certain others, and by doing so, reputations emerge for target individuals in the workplace (Hogan \& Blickle, 2013). Reputations are formed on the basis of the perceptions of others, and such perceptions are reflective of the demonstrated behavior, accomplishments, and images that are based on a target's impression management over some period of time. The consequences of a positive reputation at work include more elbowroom, power, and improved assessments of one's performance by others (Zinko, Ferris, Blass, \& Laird, 2007). Therefore, coworkers' assessments of targets' career role performance reflect targets' personal reputations for the potential to achieve career success in their organization (Blickle et al., 2018). Politically skilled target employees are more successful at creating a positive image (Blickle et al., 2018; Hogan \& Blickle, 2013), which can be part of the organizational mimicry-deception process.

\section{Mimicry-Deception Theory (MDT)}


MDT (Jones, 2014) focuses on patterns of the willingness and ability to deceive unsuspecting others. This theory identified two deceptive strategies based on patterns of deception used by either predatory nonhuman animals or parasitic infections. Mimicker predators use superficial deception tactics to overwhelm unsuspecting prey. In a short amount of time, they take as much as they can from their victims. But because the deception tactics tend to be superficial, there is an increased risk of detection of the predatory animal. Parasitic infection, by contrast, is a long-term process. The host organism is usually unaware of the penetration because complex deception tactics are used. After having achieved integration into the host organism, the parasite coexists with its host and slowly extracts resources over a long time.

MDT suggests that individuals high in MACH use one of these two overarching strategies when interacting with others in their organizations. The short-term strategy is based on superficial deception with an increased risk of detection and is aimed at immediate resource extraction. The long-term strategy employs complex deception tactics and starts by aiming at full host integration, enabling the interloper to later slowly extract resources from the organization with a low risk of detection. We expect that high MACH combined with low political skill will be associated with short-term superficial deception tactics, and high MACH combined with high political skill will be associated with the long-term complex deception strategy (Brouer, Badaway, Gallagher, \& Haber, 2015; Maher, Gallagher, Rossi, Ferris, \& Perrewé, 2018). Further, this complex strategy is aimed at secretly extracting organizational resources after achieving integration into the host organization. By delaying immediate counterproductive organizational resource extraction and curtailing their CWB when their job tenure increases, MACHs with high political skill can mask their readiness to engage in selfish and amoral actions for the sake of personal gain and advancement compared with MACHs with low political skill who are not able to suppress (during a short tenure) and effectively restrain and mask (during a long tenure) their flawed aspirations. 


\section{Hypotheses}

MACH represents the motive to get ahead at the expense of others by manipulating and betraying others when the opportunity for personal advantage or advancement is present (Dahling et al., 2009; Hogan \& Blickle, 2018). Because MACH forms part of the dark triad of personality (Paulhus \& Williams, 2002), MACH shares a number of features with these traits: "all three entail a socially malevolent character with behavior tendencies toward selfpromotion, emotional coldness, duplicity, and aggressiveness" (p. 557). In the following sections, we analyze MACHs' tendency to engage in self-promotion (i.e., reputation building), and we develop hypotheses with reference to the boundary conditions of successfully achieving a strong reputation for career role performance. After this, we turn to emotional coldness and malevolent aggressiveness (i.e., antisocial behavior at work). We argue that effective self-promotion combined with actual antisocial behavior at work constitute the fundamental duplicity achieved by those long-tenured MACHs who are highly capable social actors (Jones, 2014).

\section{Career Role Performance Reputation}

Individuals high in political skill have the ability to engage in complex deception at work. They are able to present themselves as sincere and trustworthy and can successfully use impression management tactics in the workplace (Harris, Kacmar, Zivnuska, \& Shaw, 2007). Consequently, individuals high in $\mathrm{MACH}$ and low in political skill will use more superficial deception tactics, whereas individuals high in $\mathrm{MACH}$ and high in political skill will use more complex deception tactics with different short- and long-term consequences for the assessment of career role performance by coworkers.

Specifically, for a shorter job tenure, we postulate that mainly political skill is critical for career role performance assessments by coworkers because political skill facilitates the favorable self-presentation of the whole person and not just of a single trait (i.e., $\mathrm{MACH}$; Harris et al., 2007). For a longer job tenure, we postulate that individuals high in MACH and 
high in political skill will successfully achieve integration into the host organization and build a strong reputation for career role performance, whereas individuals high in MACH but low in political skill will have a poor reputation for career role performance because their readiness to manipulate and practice deceit will not coincide with their ability to effectively and secretly do so (O’Boyle et al., 2012).

Hypothesis 1 . The relation between $\mathrm{MACH}$ and career role performance assessments by coworkers will be jointly moderated by targets' job tenure and political skill. For short job tenure, we expect that employees with high political skill will receive higher career role performance assessments from their coworkers than employees with low political skill. For long job tenure, we expect that for individuals high in political skill, MACH will be positively associated with a reputation for career role performance; and for individuals low in political skill, MACH will be negatively associated with a reputation for career role performance.

\section{Counterproductive Work Behaviors Directed toward Individuals (CWB-I)}

In line with the MACH personality construct (Christie \& Geis, 1970; Dahling et al., 2009) and socioanalytic personality theory (Hogan \& Blickle, 2018), we expect that MACH will be positively associated with anonymously self-reported CWB and that political skill will be negatively associated with anonymously self-reported CWB. On the basis of MDT, we further expect that the relation between $\mathrm{MACH}$ and anonymously self-reported CWB will be jointly moderated by targets' job tenure and political skill.

Emotional coldness has recently been meta-analytically confirmed (Monaghan, Bizumic, \& Sellbom, 2018) as an important feature of MACH (Paulhus \& Williams, 2002). It is characterized (Lilienfeld \& Widows, 2005) by “an absence of deep feelings of guilt, empathy, and loyalty, as well as a lack of enduring attachment to others" (p. 22). Weiss et al. (2019) found a convex pattern of curvilinear relations ( $)$ between emotional coldness and antisocial behaviors in a very large sample of adult criminal offenders. The positive slope increased toward the higher end of emotional coldness, indicating an increased likelihood of 
antisocial behaviors at extreme levels of emotional coldness. These convex increases probably reflect a lack of inhibition due to a lack of feelings of moral guilt, empathy, and loyalty. They are in line with findings by Zettler and Solga (2013), who reported negative quadratic effects of MACH moderated by tenure with reference to interpersonally directed organizational citizenship behavior (OCB-I), which is negatively associated with CWB-I. With longer tenure, the negative slope of MACH predicting OCB-I increased toward the higher end of $\mathrm{MACH}$. This moderating effect of tenure on the negative quadratic relation between MACH and OCB-I is in line with the predictions by MDT and Weiss et al. (2019).

In the same study, Weiss et al. (2019) also found such a convex pattern of curvilinear relations between carefree nonplanfulness and antisocial behaviors. Carefree nonplanfulness (i.e., a lack of impulse control) is characterized (Lilienfeld \& Widows, 2005) by a "lack of forethought and willingness to forgo careful consideration of alternative solutions to problems" (p. 22). Individuals high in political skill are characterized by higher levels of planfulness, strategic circumspection, and impulse control (Ferris et al., 2005, 2007, 2008). We therefore expect that individuals high in MACH (i.e., high in emotional coldness) who are politically skilled are more capable of bridling their antisocial impulses for the sake of longterm career advancement. For MACHs, this should result in a concave $(\longrightarrow$ ) pattern of curvilinear relations between MACH and CWB-I when political skill is high and a convex pattern of curvilinear relations between $\mathrm{MACH}$ and antisocial behavior when political is low.

Specifically with reference to MDT, we expect that when job tenure is short, individuals high in $\mathrm{MACH}$ and high in political skill should tend to avoid behaviors that threaten other employees' well-being (CWB-I) such as making fun of someone or hurting others. Such overtly mean behaviors toward others threaten a target's efforts to build a good reputation when job tenure is short (Jones, 2014). When MACH is high and political skill is high, the incidences of antisocial behavior toward others (CWB-I) should increase as a function of tenure because the target has achieved full host integration and therefore feels 
more secure in doing so. However, it should increase less than when political skill is low because MACHs with a long-term deception strategy (high political skill) assume that the preservation of a positive image is still important for successfully continuing to secretly extract organizational resources.

Hypothesis 2. The relation between $\mathrm{MACH}$ and anonymously self-reported counterproductive work behaviors directed toward individuals (CWB-I) will be moderated by political skill and job tenure as specified in Figure 1.

\section{Counterproductive Work Behaviors Directed toward Organizations (CWB-O)}

Secret organizational resource extraction is a form of CWB-O (Mercado, Dilchert, Giordano, \& Ones, 2018). CWB-O refers to those discretionary employee behaviors that violate organizational norms and run counter to an organization's legitimate interests (Bennett \& Robinson, 2000). Examples of hidden organizational resource extraction include taking property from work without permission, falsifying a receipt to get reimbursed for more money than spent on business expenses, coming to work late without permission, intentionally working slower than one could have worked, or dragging out work in order to get overtime. CWB-O that is closely related to secret organizational resource extraction but is not necessarily identical to it includes failing to follow the boss' instructions or discussing confidential company information with an unauthorized person.

Specifically with reference to MDT and Weiss et al.'s (2019) findings for emotional coldness and nonplanfulness, we expect that CWB-O should increase in a concave pattern of curvilinear relations in individuals high in $\mathrm{MACH}$ and political skill when they have achieved heavy integration into their organization. In other words, when $\mathrm{MACH}$ is high and job tenure is short, such behaviors should manifest in a concave pattern of resource-extracting behaviors at low levels when political skill is high (see Figure 1); and these behaviors should occur frequently when political skill is low (a convex pattern at high levels). However, when tenure is high, political skill is high, and MACH is high, the incidences of such behaviors should 
increase as a function of job tenure but should increase less than when political skill is low (a concave pattern at medium levels); such behaviors should increase only at a medium level because MACHs with a long-term deception strategy assume that the preservation of a good reputation is essential for continuing to secretly extract organizational resources.

Hypothesis 3. The relation between MACH and anonymously self-reported counterproductive work behaviors directed toward the organization (CWB-O) will be moderated by political skill and job tenure as specified in Figure 1.

\section{Overview of Studies}

We tested our research hypotheses in two different studies with a multisource triangulation (Stieglitz, 2003) to cover perceptual and behavioral domains: one for coworkers' assessments of targets' career role performance image and one for employees' self-reported CWB-I and CWB-O. In Study 1, to test Hypothesis 1, it was important to cover perceptual domains and find out how coworkers see target employees because socioanalytic theory and MDT are about creating façades for flawed personalities. We therefore analyzed employees' career-role-performance-related images, which emerged in coworkers as a function of employees' configurations of MACH and political skill, at both short and long tenures. We therefore studied the career-role-performance-related image of each employee with two coworker ratings.

In Study 2, we tested Hypotheses 2 and 3. To test these hypotheses, it was important to cover the behavioral domain and assess the real level of employees' CWB-I and CWB-O. Because CWB is a form of dark side behavior, a source with some validity is self-reported behavior because of the privileged nature of employees' knowledge of their own covert behaviors. The validity of these self-reports is enhanced when study participation is voluntary, the target person can be guaranteed complete anonymity by the researchers, and the study participants are confident in this assurance (Moshagen, Hilbig, \& Zettler, 2018). In addition, a self-deception bias with reference to CWB might be low in individuals high in $\mathrm{MACH}$ 
because their behavior is strategically calculated, and using such behaviors is part of their identity (Dahling et al., 2009). Furthermore, high political skill can potentially cover CWB from others (Castille, Kuyumucu, \& Bennett, 2017; Harvey et al., 2014; Treadway et al., 2013). As such, self-reports of CWB were expected to be more useful than other-reports in the current study. We therefore decided to ask employees to provide self-reports of their CWB on a voluntary basis in a second, independent web-based study. We provided a guarantee of complete anonymity endorsed by a university with high local prestige and a reputation for integrity. In both studies, we closely adhered the General Data Protection guidelines of the European Union (https://eugdpr.org/).

\section{Study 1}

\section{Participants and Procedures}

We contacted 565 target employees from a broad range of jobs in Germany with the help of 15 university students in partial fulfillment of their course requirements. We received complete data from 395 target employees (response rate $=69.91 \%$ ). The study hypotheses were unknown to the students. The sample diversity achieved by utilizing this type of data sampling can reduce range restriction. We asked employees if they would like to take part in an online study on personality and work behavior and if they were willing to invite two coworkers to provide a job-related assessment of their work behavior. In order to attract a broad range of participants, we offered three types of incentives to all participants: individual feedback on their social competence, entry into a prize drawing for six Amazon vouchers (€15 each), and the opportunity to donate $€ 2$ to charity. The vouchers and donations were financed by the researchers.

Each target employee received an e-mail that included information about the study and a personalized link through which to access the online survey. At the end of the selfassessment, we asked target employees to provide the e-mail addresses of two coworkers and to write a short invitation note including their name. The coworkers were directly and 
automatically sent an e-mail with an invitation to provide a brief job-related assessment of the individual they had received the invite from. All participants were informed that confidentiality would be preserved by the use of randomly generated codes. Using these codes, we were able to link target employees' self-assessments to the corresponding coworker assessments while simultaneously granting confidentiality to all participants.

The 395 target employees with complete data asked 657 coworkers to provide career role performance assessments. For our final sample, we focused on the 251 target employees who were rated by two coworkers (397 peers, 79 subordinates, 26 supervisors) with reference to career role performance. We compared these target employees who had two coworker ratings with the other target employees with reference to gender, age, number of weekly working hours, years of job tenure, $\mathrm{MACH}$, political skill, and career role performance using one-way ANOVAs and chi-square difference tests. The tests revealed only one significant group difference, namely, for age, $F(1,393)=5.52, p=.019$, but the effect was small $\left(\hat{\eta}^{2}=\right.$ $.014)$. The group with two coworker ratings was older $(M=43.01, S D=12.37)$ than the group with one or no coworker ratings $(M=39.97, S D=12.40)$. As we statistically controlled for age, this difference could not bias our results.

\section{Measures}

Machiavellianism (MACH). We used a validated German adaptation (Zettler \& Solga, 2013) of the Machiavellian Personality Scale (MPS; Dahling et al., 2009). The MPS consists of 16 items. Sample items are "I would cheat if there was a low chance of getting caught," "I enjoy having control over other people," "Status is a good sign of success in life," and "People are only motivated by personal gain." Participants indicated their responses on a 5-point scale ranging from 1 (strongly disagree) to 5 (strongly agree). Cronbach's alpha for the MACH scale was .84 .

Political Skill (PS). Targets' political skill was measured with the 18 self-rating items from the Political Skill Inventory (PSI; Ferris et al., 2005). A cross-culturally validated 
German translation of the self-report PSI (Ferris et al., 2008; Lvina et al., 2012) was used. This self-report tool for assessing social skill at work has been validated in several metaanalyses (Bing et al., 2011; Jacobson \& Viswesvaran, 2017; Munyon et al., 2015). The convergent validity between self- and coworker reports of political skill supports the suggestion that self-ratings of political skill realistically assess actual political skill as perceived by coworkers (Blickle, Ferris, et al., 2011; Ferris et al., 2008; Meurs, Gallagher, \& Perrewé, 2010). Also, self-reports of political skill provide a superior contribution to criterion validity in comparison with other social effectiveness constructs such as leadership selfefficacy, self-monitoring, and emotional intelligence (Semadar et al., 2006). Sample items are "I am able to communicate easily and effectively with others," "I am particularly good at sensing the motivations and hidden agendas of others," "At work, I know a lot of important people and am well connected," and "It is important that people believe I am sincere in what I say and do." Target employees rated their level of political skill on a 7-point Likert-type scale ranging from 1 (strongly disagree) to 7 (strongly agree). Cronbach's alpha was .89.

Tenure. We asked individuals to report how long they had held their current job. The average job tenure was 10.74 years $(S D=9.27, \operatorname{Min}=1$ month, $\operatorname{Max}=38$ years, $\operatorname{Mdn}=8.25$ years). In the total German workforce, the average job tenure is 11.1 years (Rodriguez \& Guest, 2010).

Career role performance (CRP). Targets' career behavior was assessed by two coworkers with the validated German version of the Career Role Behavior Scale (Welbourne et al., 1998) by Zettler, Kramer, Thoemmes, Nagy, and Trautwein (2013).

The measure has been broadly used in related research (e.g., Zacher, 2015). The four items are "Obtaining personal career goals," "Developing skills needed for his/her future career," "Making progress in his/her career," and "Seeking out career opportunities" (Welbourne et al., 1998, p. 554). Coworkers used rating anchors ranging from 1 (poor) to 5 (very good). 
Rater agreement between the two coworkers $\left(\operatorname{ICC}[1,1]=.56 ; \operatorname{ICC}[1, \mathrm{k}]=.72 ; r_{w g}: M=.84\right.$, $\operatorname{Min}=-1.25, \operatorname{Max}=1, \operatorname{Mdn}=.94)$ was sufficiently high to be aggregated by forming the mean (LeBreton \& Senter, 2008). Cronbach's alpha for the aggregated ratings was $\alpha=.87$. A validation study confirmed the discriminant validity of the CRP scale with reference to proactive behavior at work (see the Appendix for details).

Control variable. Given that increases in job tenure are naturally accompanied by increases in chronological age, the level of career role performance that employees with a long tenure are expected to display might differ from the performance of younger employees (Waldman \& Avolio, 1986). Consequently, we asked participants to report their chronological age and controlled for it in our statistical analyses in order to separate the effects of job tenure from chronological age.

\section{Statistical Analyses}

To evaluate the independence and distinctiveness of our rating scales, we compared two different models in Mplus 7.0 (Muthén \& Muthén, 2012). In the first model, we built one factor for the self-ratings (MACH, political skill) and another factor for the other-ratings of career role performance. In the second model, we modeled each construct as a separate factor. The CFA revealed the following indices for the two-factor model $\left(\chi^{2}=2853.48, d f=664\right.$, $\left.\chi^{2} / d f=4.30, \mathrm{RMSEA}=.115, \mathrm{SRMR}=.136\right)$. The indices for the three-factor model were generally better $\left(\chi^{2}=2151.19, d f=662, \chi^{2} / d f=3.25, \operatorname{RMSEA}=.095, \operatorname{SRMR}=.101\right)$. Compared with the two-factor model, the overall fit of the three-factor model was significantly better $\left(\Delta \chi^{2}=702.29, \Delta d f=3, p<.05\right)$. Overall, the results supported the distinctiveness and uniqueness of the rating scales used to operationalize our constructs of interest in Study 1. Assuming an incremental effect size of $3 \%$ of the three-way interaction (Parker, Jimmieson, $\&$ Amiot, 2009), $\alpha=.05$, and $1-\beta=.80$, the necessary sample size was $N$ $=250$ (Faul, Erdfelder, Buchner, \& Lang, 2009). 
We tested Hypothesis 1 with a multiple hierarchical moderated regression analysis. Following Cohen, Cohen, West, and Aiken (2003), in the first step (see Table 2: Model 1a) we entered the control variable, MACH, political skill, and tenures. In the second step (see Table 2: Model 1b), we entered the two-way interaction variables. In the third step (see Table 2: Model 1c), we tested the three-way interaction of MACH x Political Skill x Tenure. A significant three-way interaction was a first step to support Hypothesis 1 . For further inquiry we plotted the interactions as specified by Dawson (2014). To address multicollinearity, all linear predictors were standardized prior to building the interaction terms. Finally, non-linear effects were tested.

\section{Results}

As can be seen in Table 1a, age correlated with tenure $(r=.60, p<.05)$, and coworker assessments of targets' career role performance were positively correlated with targets' political skill $(r=.27, p<.05)$.

The results of the test of Hypothesis 1, implying a three-way interaction between $\mathrm{MACH}$, political skill, and job tenure, can be found in Table 2 (Model $1 \mathrm{c}, \beta=0.14, p<.05$ ). The residuals of the dependent variable were normally distributed (Model 1c: skewness = 0.36 , kurtosis $=0.48)$. Zero values of skewness and kurtosis represent perfectly normal distributions, whereas skewness $> \pm|2|$ and kurtosis $> \pm|7|$ are indicative of non-normal distributions (Curran, West, \& Finch, 1996). Additionally, there was no variance inflation factor (VIF) value above 10, the highest value being 1.62, indicating that multicollinearity was not a concern and supporting the statistical adequacy of our regression models (Tabachnick \& Fidell, 2013). These findings remained essentially the same also when we included the interactions with the quadratic MACH term in the analyses and when we excluded all targets with tenures beyond 30 years from the analyses. This demonstrates that our findings are robust and not driven by outliers. 
Next we probed this three-way interaction and plotted the relations between targets' $\mathrm{MACH}$ and targets' career role performance at one $S D$ above and below the mean of tenure. This plot is depicted in Figure 2a.

For a short job tenure, we expected that employees with high political skill would receive higher career role performance assessments from their coworkers than employees with low political skill. As Figure 2 shows, the plot confirmed this expectation. For a long job tenure, we expected that for individuals high in political skill, MACH would positively predict a reputation for career role performance; and for individuals low in political skill, $\mathrm{MACH}$ would negatively predict a reputation for career role performance. In line with these expectations, for a long tenure, we found a positive slope for $\mathrm{MACH}$ at high levels of political skill $(B=0.14, t=1.41, n s)$ and a negative slope for MACH at low levels of political skill $(B$ $=-0.27, t=-2.80, p<.05)$. The slopes of high political skill at high tenure and low political at high tenure differed significantly $(t=3.13, p<.05)$. Consequently, the reputations of employees high (vs. low) in $\mathrm{MACH}$ at low tenure were higher than at high tenure when employees were low (vs. high) in political skill (see Figure 2a).

Additionally, we conducted the same analyses for the individual facets of political skill. We also found the three-way interaction with the same shape for social astuteness, networking ability, and apparent sincerity. For apparent sincerity and high tenure, we also found a convex pattern of curvilinear relations between $\mathrm{MACH}$ and $\mathrm{CRP}$, indicating the special role apparent sincerity might play in masking malevolent social behavior at work. In an additional data analysis (Hayes, 2015), we conducted a moderated mediation analysis to investigate the relation between $\mathrm{MACH}$ as a predictor, reputation for career role performance as a mediator, and hierarchical position as an outcome variable. When tenure was high and political skill was low, MACH indirectly negatively predicted targets' hierarchical position; indirect effect $=-1.551(S E=.9674, \mathrm{LLCI}=-3.953, \mathrm{ULCI}=-.165)$. 
This finding additionally supported the objective career relevance (hierarchical position) of the reputation for career role performance (CRP coworker rated).

Additionally, we found a two-way interaction between MACH and political skill (Table 2, Model 1c, $\beta=0.16, p<.05$ ). The shape of the interaction is depicted in Figure $2 \mathrm{~b}$. When political skill was high, career role performance assessments from coworkers were also high, irrespective of targets' $\mathrm{MACH}$; when political skill was low, however, career role assessments decreased as MACH increased $(B=-0.14, t=-2.72, p<.05)$. When we used $+/-2$ $S D$ for $\mathrm{MACH}$, the shapes of the plots in Figure 2 remained essentially the same as in Figure $2 b$.

Exploratory sensitivity analyses. Finally, to test the differential validity of the tenure and chronological age variables, we analyzed Sample 1 without the control variable (see Table 2a in the Appendix) as well as with tenure as a control variable and age as a moderating variable (see Table $2 \mathrm{~b}$ in the Appendix). Without the control variable (Appendix Table 2a), the interaction of MACH x PS x Tenure was still significant. For age, we did not find the three-way interaction that we found for tenure (see Table $2 \mathrm{~b}$ in the Appendix). We also tested the MACH x PS x Tenure x Age interaction, but it was not significant (Appendix Table 4a). In sum, these results confirmed the difference between the tenure and age variables in Study 1.

\section{Brief Discussion of Study 1}

The findings of Study 1 supported MDT: High MACH individuals with high (as opposed to low) political skill can effectively hide their readiness to engage in selfish and amoral actions for the sake of personal gain and advancement; instead, they enjoy a good reputation for career role performance with their coworkers. Study 2 was designed to test whether the positive image of those with high MACH and high political skill is based on the fact that they are able to curtail their dark aspirations and keep their CWB at a low level when job tenure is short so that they can become well-integrated into the organization. If MDT is 
correct, when the tenure of MACHs is long, interpersonal harm (CWB-I) and organizational misbehavior (CWB-O) are higher. However, the dose of CWB enacted by high MACHs at long tenure should be at such a well-calculated level that positive evaluations from coworkers will not be jeopardized. Study 1 showed that those with high $\mathrm{MACH}$ and high political skill indeed still enjoyed a good reputation with their coworkers at high job tenure. Consequently, Study 2 was designed to clarify whether this positive reputation at long tenure of those high in MACH would simultaneously be associated with elevated levels of CWB.

A limitation of this study results from allowing the focal individuals to select their raters. Presumably, focal individuals gave the survey to those with whom they have a stronger exchange relationship, which could have resulted in range restriction and thereby reduced the statistical power for detecting existing differences. However, there are also a few instances (e.g., polarized feelings toward the focal employee resulting in restriction due to a missing middle) which could inflate the effect sizes (Sackett \& Yang, 2000).

Using the incremental effect size of the three-way interaction in Study $1\left(\Delta R^{2}=\right.$ 0.019), we computed a post hoc power $(\alpha=.05)$ analysis (Faul et al., 2009), which indicated a power of $1-\beta=.59$. Because this was suboptimal (Cohen, 1992), we sampled many more target study participants for Study 2 than we had in Study 1.

\section{Study 2}

\section{Participants and Procedures}

We received complete data from 685 employees (response rate $=82.50 \%$ ) in Germany. We asked university students to help with the data collection. They contacted a total of 830 employees from a broad range of jobs. As in Study 1, the students were not aware of the hypotheses. We asked the contacted employees if they were willing to take part in an online study on personality and self-interest at work. To attract a broad range of participants, we offered different types of incentives to attract different kinds of participants: individual feedback on their social competence, entry into a raffle for six Amazon vouchers (€15 each), 
and the opportunity to donate $€ 2$ to charity. The vouchers and donations were financed by the researchers. In addition, participants could win $€ 5$ in a gambling task. If they won, they could either take the prize money or add the amount to the donation.

To credibly convince participants of the anonymity of their answers, we designed a multistage study and made the procedure transparent to them: First, participants received a pseudonymized link to the introduction of the study, which was used to account for the number of participants each student acquired. Second, they were forwarded to an anonymous survey including the relevant measures of this study. Third, they were again forwarded to another webpage where they could leave their contact details for the prize drawing, learn who won the drawing, or get information about the results of the study. The questionnaire was programmed with a certified platform that used a secure socket layer encryption technology to prevent the data from being read or manipulated by a third party (i.e., EFS survey, Questback AG, https://www.unipark.com/en/data-security/). Finally, we asked participants at the end of the questionnaire if their responses reflected their actual work behavior. In sum, $98.20 \%$ reported that that they had answered honestly. This indicated that we were successful in creating a setting for participants to respond candidly and freely without concerns.

\section{Measures}

Machiavellianism (MACH), Political Skill (PS), and Tenure. We used the same predictor measures as in Study 1. Cronbach's alpha for the MACH scale was .87 and .90 for political skill. The average job tenure was 9.46 years $(S D=9.46, \operatorname{Min}=1$ month, $\operatorname{Max}=45$ years, $\operatorname{Mdn}=5.33$ years $)$.

Counterproductive work behavior (CWB). Targets' CWB-I and CWB-O were selfassessed with the German version (Zettler \& Hilbig, 2010) of Bennett and Robinson's (2000) 19-item Workplace Deviance Scale. The measures have been widely used in related research (i.e., Mount, Ilies, \& Johnson, 2006). The CWB-O scale comprises 12 items and the CWB-I scale 7 items. A CWB-O sample item is "Falsified a receipt to get reimbursed for more 
money than you spent on business expenses." A CWB-I sample item is "Played a mean prank on someone at work." Target employees used rating anchors ranging from 1 (never) to 7 (daily). Cronbach's alpha was $\alpha=.84$ for CWB-I and $\alpha=.83$ for CWB-O.

Control variable. Given that increases in job tenure are naturally accompanied by increases in chronological age and given the well-established negative relation between chronological age and CWB (Ng \& Feldman, 2008), we asked participants to report their chronological age and controlled for it in our statistical analyses in order to separate the effects of job tenure from chronological age.

\section{Data Analyses}

To assess the uniqueness and distinctiveness of the different measures, we ran several confirmatory factor analyses. In the first model, we built one factor for the self-ratings of MACH, political skill, CWB-I, and CWB-O. In the second model, we modeled each construct as a separate factor. The CFA revealed the following indices for the one-factor model $\left(\chi^{2}=\right.$ $\left.11264.25, d f=1325, \chi^{2} / d f=8.50, \mathrm{RMSEA}=.105, \mathrm{SRMR}=.137\right)$. The indices for the fourfactor model were generally better $\left(\chi^{2}=6055.11, d f=1319, \chi^{2} / d f=4.59 ;\right.$ RMSEA $=$ $.072, \mathrm{SRMR}=.081)$. Compared with the one-factor model, the fit of the four-factor model was significantly better $\left(\Delta \chi^{2}=5209.14, \Delta d f=6, p<.05\right)$. Overall, the results again supported the distinctiveness and uniqueness of the rating scales used to operationalize our constructs of interest in Study 2.

We tested Hypotheses 2 and 3 with multiple hierarchical moderated regression analyses that included the quadratic component of $\mathrm{MACH}$ and its interactions with the other variables in the analyses (Evans, 1991) to assess the convex and concave curvilinear relations with CWB. Because our predictor and moderator variables were correlated (see Table 1b), we additionally had to control for the quadratic terms of the moderator variables (Cortina, 1993). To avoid the negative consequences of multicollinearity, all linear predictors were standardized prior to building the interaction and the quadratic terms and analyses. 


\section{Results}

As can be seen in Table $1 \mathrm{~b}$, age was correlated with tenure $(r=.63, p<.05)$, and selfreports of CWB-I and CWB-O were correlated with age, $\mathrm{MACH}$, political skill, and job tenure. The results of the test of Hypotheses 2 and 3 can be found in Table 3.

A significant interaction of political skill and tenure with the quadratic term of $\mathrm{MACH}$ was a first step to support Hypotheses 2 and 3. In both statistical models, the data supported the interaction of the quadratic MACH-term with political skill and tenure with reference to CWB-I (Hypothesis 2: Table 3, Model 2c, $\beta=-0.16, p<.05$ ) and CWB-O (Hypothesis 3: Table 3, Model $3 c, \beta=-0.17, p<.05)$. In addition, the residuals of the dependent variables were in the acceptable range (Model 2c: skewness $=1.73$, kurtosis $=4.94$; Model 3c: skewness $=1.25$, kurtosis $=2.64$; Curran et al., 1996). As in Study 1, all VIF values were below 10 , with the highest value at 4.18 , indicating that multicollinearity was not a concern and supporting the statistical adequacy of our regression models (Tabachnick \& Fidell, 2013). These findings remained essentially the same also when we excluded all targets with tenures beyond 30 years or less than one year from the analyses. This demonstrates that our findings were robust and not driven by outliers. Using the incremental effect sizes of the two quadratic three-way interactions in Study 2 (Table 3: $\Delta R^{2}$ CWB-I $=0.013, p<.05 ; \Delta R^{2}$ CWB-O $=0.012, p<$ $.05)$, we computed a post hoc power analysis $(N=685 ; \alpha=.05$; Faul et al., 2009). It indicated sufficient statistical power, with $1-\beta=.85$ and $1-\beta=.82$, respectively (Cohen, 1992).

We also plotted the interactions as specified by Dawson (2014). This involved testing the relation between the predictor and the criterion at specific values of the moderators. Cohen et al. (2003) recommended picking $1 S D$ above and below the mean, which marked the upper and lower $15 \%$ of the normal probability distribution. Because of the left skewed distribution of tenure in Study 2 (skewness $=1.23), 1 S D$ below the mean would have been a negative tenure value, which did not exist. We therefore chose to pick the points of the distribution that marked the upper (tenure $=21.59$ years) and lower (tenure $=2.58$ years) $15 \%$ of the tenure 
distribution in Study 2. The upper part of Figure 3 depicts the relations for CWB-I and the lower part of Figure 3 depicts the relations for CWB-O.

MDT (Hypothesis 2) proposed that when job tenure was low, individuals high in $\mathrm{MACH}$ and high in political skill would tend to avoid displaying overtly mean behaviors toward others because that would threaten a target's efforts to build his/her reputation. As the upper part of Figure 3 (see dependent variable $=$ CWB-I) shows, individuals with Mean $\leq$ $\mathrm{MACH} \leq 1 S D$ levels of $\mathrm{MACH}$ and with low tenure and high political skill indeed anonymously reported engaging in the lowest level of CWB-I compared with other combinations of political skill and tenure. Additionally, MDT implies that when MACH is high and political skill is high, the incidences of CWB-I should increase as a function of job tenure because, at higher tenure, the target has achieved organizational integration and should therefore feel secure in doing so. However, CWB-I should increase less than when political skill is low (i.e., use of short-term superficial deception tactics) because the long-term preservation of a positive image is still important for successfully continuing to secretly extract organizational resources. As the upper part of Figure 3 shows, the findings of CWB-I supported this implication of MDT and thus supported Hypothesis 2 for Mean $\leq \mathrm{MACH} \leq 1$ $S D$ levels of $\mathrm{MACH}$. However, when $\mathrm{MACH}$ was very high (i.e., $\mathrm{MACH} \geq 1.7 S D$ ), already at low tenure, the level of CWB-I reached the level of CWB-I at high tenure, that is, these slopes increased convexly instead of decreasing concavely (see Figure 1 and upper part of Figure 3). This finding is not in line with the predictions implied by MDT

Additionally, we conducted the same analyses with the individual facets of political skill. We found the significant quadratic three-way interaction with the same shape for all facets. For social astuteness and networking ability, the shapes of the convex and concave relations were closer to Hypothesis 2 than for interpersonal influence and apparent sincerity.

We found the same pattern for CWB-O (Hypothesis 3, lower part of Figure 3) as for CWB-I (Hypothesis 2). When MACH was very high (i.e., $\mathrm{MACH} \geq 1.3 \mathrm{SD}$ ), already at low 
tenure, the level of CWB-O reached the level of CWB-O at high tenure. The pattern of relations was essentially the same when we eliminated the items for assessing vandalism, drug abuse, and absenteeism from the CWB-O scale and focused on the theft, fraud, and leaking items. This finding was also not in line with the predictions implied by MDT. Next, we conducted the same analyses with the individual facets of political skill. We found the significant quadratic three-way interaction with the same shape for all facets of political skill. Additionally, we found two two-way interactions between MACH and political skill (CWB-I: Table 3, Model 2c, $\beta=-0.11, p<.05$; CWB-O: Table 3, Model 3c, $\beta=-0.11, p<$ .05). The shapes of the interactions are depicted in Figure 4. When political skill was high, the slope of MACH in predicting CWB-I $(B=0.22, t=4.86, p<.05)$ and CWB-O $(B=0.15, t=$ $3.22, p<.05)$ was lower than when political skill was low (CWB-I: $B=0.39, t=8.73, p<$ .05 ; CWB-O: $B=.29, t=6.55, p<.05)$. Thus, although CWB increased with MACH, it increased less when political skill was high. When we used +/-1 SD for $\mathrm{MACH}$, the shapes of the plots in Figure 4 remained essentially the same.

Exploratory sensitivity analyses. Finally, to test the differential validity of the tenure and chronological age variables, we analyzed Sample 2 without the control variable (see Table 3a in the Appendix) as well as with tenure as a control variable and age as a moderating variable (see Table 3b in the Appendix). Without the control variable (Appendix Table 3a), the interaction of Mach x MACH x PS x Tenure was still significant. For age, we did not find the interaction we found for tenure (see Table $3 \mathrm{~b}$ in the Appendix). We also tested the Mach $\mathrm{x}$ MACH $x$ PS $x$ Tenure $x$ Age interaction, but it was not significant (see Tables $4 \mathrm{~b}$ and $4 \mathrm{c}$ in the Appendix). In sum, these results confirmed the difference between the tenure and age variables in Study 2.

\section{Brief Discussion of Study 2}

In sum, our findings partly supported the idea that individuals with increased levels of $\mathrm{MACH}($ Mean $\leq \mathrm{MACH} \leq 1 S D$ above the mean of MACH) and political skill (1 $S D$ above 
the mean of political skill) enacted lower levels of CWB-I (Hypothesis 2) and CWB-O (Hypothesis 3) at low job tenure as opposed to high job tenure. At low job tenure, they refrained from engaging in CWB to create a positive image, but at high job tenure, high MACHs enacted interpersonal harm (CWB-I) and organizational misbehavior (CWB-O).

However, our findings also partly disconfirmed predictions from MDT: When MACH was at a high (for $\mathrm{CWB}-\mathrm{O}, \mathrm{MACH} \geq 1.3 \mathrm{SD}$ ) or very high level (for CWB-I, $\mathrm{MACH} \geq 1.7$ $S D$ ), and even when levels of political skill were high, both CWB-I and CWB-O were enacted at higher levels at low job tenure than at high job tenure. Individuals high in $\mathrm{MACH}$ and high in political skill obviously do not tend to avoid engaging in overtly mean behaviors toward others and extracting organizational resources at short tenure although that might threaten a target's reputation-building efforts. Consequently, targets high in $\mathrm{MACH}$ and political skill do not display complete short-term self-restraint with reference to antisocial workplace behaviors. In the General Discussion, we look at the broad implications of these findings.

\section{General Discussion}

Political skill can expose the upside of dark personality traits or effectively mask their dark core at work. In this study, using two workplace samples, we analyzed and tested the relations between the dark triad personality trait of $\mathrm{MACH}$ and political skill and the effects of MACH on coworkers' perceptions of targets' career role performance and self-reported CWB in workers with low and high tenure. On the basis of socioanalytic personality theory and mimicry-deception theory (MDT), we hypothesized that high political skill would mask the dark core of individuals high in $\mathrm{MACH}$ so that workers could successfully deceive their coworkers at short tenure and harm their organizations and secretly extract resources at long tenure.

In Study 1, we tested how coworkers assessed targets' career role performance. In target workers with low tenure, we found that the image of career role performance critically depended upon political skill. Individuals high in $\mathrm{MACH}$ got high performance ratings if they 
also scored high on political skill. Thus, high scores on political skill effectively masked individuals high in $\mathrm{MACH}$. In workers with high tenure, MACH was the functional driver of the career role performance image in coworkers moderated by targets' political skill: If targets scored high on political skill, MACHs had a positive reputation for career role performance. If targets scored low on political skill, increasing $\mathrm{MACH}$ predicted a decreasing reputation for career role performance, which mediated the relation between $\mathrm{MACH}$ and hierarchical position. In sum, high political skill effectively masked the dark dispositions and reinforced MACHs' image building at work. At low levels of political skill and high tenure, MACH was negatively associated with hierarchical position mediated by a reputation for career role performance.

In Study 2, we tested targets' CWB-I and CWB-O by using self-reports in a completely anonymous setting that gave participants the chance to respond candidly and freely without concerns. Contrary to MDT, we found that individuals very high in MACH and high in political skill did not tend to avoid engaging in overtly mean behaviors toward others and extracting organizational resources at short tenure. However, as Study 1 showed, this was not associated with significant decreases in a target's reputation among coworkers. Our findings thus indicate that political skill generally camouflages $\mathrm{MACH}$ no matter how long the target has been with the organization. Political skill reduces the amount of CWB-I and CWB-O enacted (see Figure 4), but irrespective of political skill, CWB-I and CWB-O increase with increases in $\mathrm{MACH}$, i.e., targets high in $\mathrm{MACH}$ and high in political skill nevertheless use short-term antisocial behavior. And as long as political skill is high, this is not associated with decreases in reputation (see Figure $2 \mathrm{~b}$ ).

\section{Contributions to Theory and Research}

This study makes a few notable contributions to the socioanalytic personality theory, MDT, and MACH literatures. First, this study provides support for socioanalytic theory in that results indicate that individuals who are politically skilled are more capable of translating 
their basic motives (i.e., to get ahead) into successful action (Hogan \& Shelton, 1998). In addition, this research also demonstrates that the basic tenets of socioanalytic theory hold true even for individuals characterized by some of the more aberrant personality traits. In addition, it extends previous research on bullying and leadership (Harvey et al., 2014; Treadway et al., 2013) by examining political skill as a means for effectively masking the antisocial behavior of MACHs with reference to a reputation for career role performance; however, masking does not imply a complete short-term curtailing of antisocial behavior as suggested by mimicrydeception theory (Jones, 2014). Consequently, this suggests that the long-term vocational success of targets high in MACH and high in political skill might not be achieved through heavy short-term self-restraint at work. This is remarkable because we found that counterproductive work behavior convexly increased at low tenure and high political skill with increasing MACH. These results replicate Weiss et al.'s (2019) findings from a criminal offender study with reference to emotional coldness and antisocial behavior. These convex increases probably reflect a lack of inhibition due to a lack of feelings of moral guilt, empathy, and loyalty. Thus, another contribution of our research is that it helps close the gaps between the different lines of research in forensic and I-O psychology.

Along these lines, this study is the first of its kind to empirically examine the role of job tenure in MDT. However, MDT's general predictions concerning the role of tenure were not supported by our data, especially not, when MACH was very high. Complementarily, MDT suggests that individuals who use the short-term deception strategy, which is based on superficial deception with an increased risk of detection and aimed at immediate resource extraction, tend to quit organizations early. But why is it possible for some people who practice this short-term strategy (i.e., individuals high in $\mathrm{MACH}$ and low in political skill) to persist and even hold their job for a long time? We think that other factors besides deception strategies also influence the amount of job tenure (e.g., target workers' task proficiency, worker friendly labor market regulations that make it difficult for organizations to dismiss 
problematic workers, and the difficulty of replacing a worker in a specific job) because the labor market work force is shrinking due to demographic change (Roth, Wegge, \& Schmidt; 2007). All these characteristics apply to the German labor market: Average workers are welleducated and have good task proficiency (European Center for the Development of Vocational Training, 2017), labor market regulations in Germany are worker friendly (Dribbusch \& Birke, 2012), and the labor market pool is shrinking due to demographic change (Allmendinger \& Ebner, 2006). Consequently, future research should elaborate on how workers who repeatedly openly practice CWB-O and CWB-I are able to persist in their organizations.

\section{Contributions to Practice and Future Research}

The primary practical implication of our studies with reference to career behavior is that individuals high in $\mathrm{MACH}$ and low in political skill display low vocational adjustment at both short and long tenure. This implication is in line with previous research on the consequences of distrustful beliefs about human nature (Stavrova \& Ehlebracht, 2016), which is an important feature of MACH. Individuals high in distrust who assume that others are exploitive and dishonest are less likely to provide and receive social support and are more likely to avoid cooperation. They are in command of less social capital, and they overinvest in monitoring and controlling others in order to avoid possible exploitation. Only in sociocultural contexts with low levels of prosocial behavior and high overall societal cynicism (i.e., when cynical beliefs hold true) does a positive relation between distrust and income emerge (Stavrova \& Ehlebracht, 2016).

A practical vocational implication of equal importance is that $\mathrm{MACH}$ can be nearly perfectly masked by high political skill. Our research demonstrated that these individuals received high career performance ratings by their unsuspecting coworkers in both the short and long runs and that they were able to successfully keep their CWB at a lower level. However, their dark core was more apparent at higher levels of MACH. Future research 
should investigate which kinds of organizations and job demands attract individuals high in $\mathrm{MACH}$ and high in political skill, whether and why there were no red flags when these individuals were hired, and how it is possible for these individuals to persist in organizations instead of getting fired.

Because of their highly skillful social behavior, it seems at first glance that conventional selection-approach-based personality questionnaires should not be able to identify these individuals because of their near perfect faking skills. However, individuals also have a desire to express their identity in personality questionnaires (Johnson \& Hogan, 2006) in personnel selection situations (Hogan, Barrett, \& Hogan, 2007). And a strong marker of a MACH identity is a distrustful and cynical view of human nature (e.g., Christie \& Geis, 1970; Dahling et al., 2009). Because such beliefs are taken as indications of competence and intelligence by laypersons (Stavrova \& Ehlebracht, 2019), even though individuals high in $\mathrm{MACH}$ probably try not to disclose their willingness to act amorally for personal gain on personality questionaires in personnel selection situations, they are likely to candidly express their distrustful and cynical views of human nature in personnel selection situations to create an image of competence and intelligence in the eyes of the beholders. Therefore, there is a good chance of detecting such nearly perfectly masked individuals' high MACH even when political skill is high. Future research should test this approach using within-person designs with real job applicants (Hogan et al., 2007).

\section{Limitations and Strengths}

Our studies are not without limitations. The cross-sectional nature of our studies limit conclusions about causation. Additionally, the cross-sectional nature of our studies does not permit a within-subjects evaluation to see if/how individuals change as a function of tenure. Next, we did not measure the different behavioral strategies (e.g., impression management strategies) employed by MACHs and politically skilled individuals. Therefore, we are left to assume that there is a difference, but we do not know how the behaviors differ. To 
specifically assess these differences in the use of impression management tactics, future research might not only use the assessment of impression management tactics (Bolino, Long, \& Turnley, 2016) but also the MACH planfulness scale (comprising deliberation and order) by Collison, Vize, Miller, and Lynam (2018).

Although both samples were quite large ( $N_{1}=3 \times 251, N_{2}=685$ participants), a larger sample in Study 1 would have been desirable. However, the interaction between MACH and political skill was a recurring pattern in both samples, one with a monosource and one with a heterosource design (Podsakoff et al., 2012). This triangular design (Stieglitz, 2003) is a strength of our research focusing on perceptual (i.e., coworker assessments of employees' career role performance) and behavioral (i.e., candid self-reports of CWB) domains. Additional replications and meta-analyses are needed.

\section{Conclusion}

With this study, we supported predictions from socioanalytic personality theory that high political skill can effectively mask MACH in the workplace with implications for a target's reputation for career role performance. We suggest that employers use the selfdisclosure of distrustful and cynical views of human nature as markers in personnel selection to crack this nearly perfect mask of benignancy. Contrary to the predictions of mimicrydeception theory, we found that individuals high in MACH and high in political skill do not strongly self-restrain from counterproductive work behavior. 


\section{References}

Allmendinger, J., \& Ebner, C. (2006). Labor market and demographic changes: the future of employment in Germany [Arbeitsmarkt und demografischer Wandel: Die Zukunft der Beschäftigung in Deutschland]. German Journal of Work and Organizational Psychology, 50, 227-239.

Bedell, K., Hunter, S., Angie, A., \& Vert, A. (2006). A historiometric examination of Machiavellianism and a new taxonomy of leadership. Journal of Leadership and Organizational Studies, 12, 50-72.

Bennett, R. J., \& Robinson, S. L. (2000). Development of a measure of workplace deviance. Journal of Applied Psychology, 85, 349-360.

Bing, M. N., Davison, H. K., Minor, I., Novicevic, M. M., \& Frink, D. D. (2011). The prediction of task and contextual performance by political skill: A meta-analysis and moderator test. Journal of Vocational Behavior, 79, 563-577.

Blau, P. M. (1964). Exchange and power in social life. New York: Wiley.

Blickle, G., Ferris, G. R., Munyon, T. P., Momm, T.E., Zettler, I., Schneider, P. B. \& Buckley, M. R. (2011). A multi-source, multi-study investigation of job performance prediction by political skill. Applied Psychology: An International Review, 60, 449474.

Blickle, G., Frieder, R., \& Ferris, G. R. (2018). Political skill. In D. S. Ones, N. R. Anderson, C. Viswesvaran, \& H. K. Sinangil (Eds.), The SAGE Handbook of Industrial, Work \& Organizational Psychology: Personnel Psychology and Employee Performance (pp. 299-319). Los Angeles, USA: Sage.

Blickle, G., Schneider, P. B., Liu, Y., \& Ferris, G. R. (2011). A predictive investigation of reputation as mediator of the political skill - career success relationships. Journal of Applied Social Psychology, 41, 3026-3048. 
Bolino, M. C., Long, D., \& Turnley, W. H. (2016). Impression management in organizations: Critical questions, answers, and areas of future research. Annual Review of Organizational Psychology and Organizational Behavior, 3, 377-406.

Brouer, R. L., Badaway, R. L., Gallagher, V. C., \& Haber, J. A. (2015). Political skill dimensionality and impression management choice and effective use. Journal of Business and Psychology, 30, 217-233.

Castille, C. M., Kuyumucu, D., \& Bennett, R. J. (2017). Prevailing to the peers' detriment: organizational constraints motivate Machiavellians to undermine their peers. Personality and Individual Differences, 104, 29-36.

Christie, R., \& Geis, F. L. (1970). Studies in Machiavellianism. New York, NY: Academic Press.

Cohen, A. (1992). A power primer. Psychological Bulletin, 112, 155-159.

Cohen, J., Cohen, P., West, S., \& Aiken, L. (2003). Applied multiple regression/correlation analysis for the behavioral sciences. Mahwah, NJ: Lawrence Erlbaum.

Collison, K. L., Vize, C. E., Miller, J. D., \& Lynam, D. R. (2018). Development and preliminary validation of a Five Factor Model measure of Machiavellianism. Psychological Assessment, 30, 1401-1407.

Cortina, J. M. (1993). Interaction, nonlinearity, and multicollinearity: implications for multiple regression. Journal of Management, 19, 915-922.

Curran, P. J., West, S. G., \& Finch, J. F. (1996). The robustness of test statistics to nonnormality and specification error in confirmatory factor analysis. Psychological Methods, 1, 16-29.

Dahling, J. J., Whitaker, B. G., \& Levy, P. E. (2009). The development and validation of a new Machiavellianism scale. Journal of Management, 35, 219-257.

Dawson, J. F. (2014). Moderation in management research: what, why, when, and how. Journal of Business and Psychology, 29, 1-19. 
DePaulo, B. M., \& Rosenthal, R. (1979). Telling lies. Journal of Personality and Social Psychology, 37, 1713-1722.

Dribbusch, H., \& Birke, P. (2012). Trade unions in Germany: Organization, environment, challenges. International Trade Union Policy, May, pp. 1-19.

European Center for the Development of Vocational Training (2017). Spotlight on VET Germany. Thessaloniki: Gr.

Evans, M. G. (1991). The problem of analyzing multiplicative composites. Interactions revisited. American Psychologist, 46, 6-15.

Faul, F., Erdfelder, E., Buchner, A., \& Lang, A. G. (2009). Statistical power analyses using G*Power 3.1: Tests for correlation and regression analyses. Behavior Research Methods, 41, 1149-1160.

Ferris, G. R., Blickle, G., Schneider, P. B., Kramer, J., Zettler, I., Solga, J., Noethen, D., \& Meurs, J.A. (2008). Political skill construct and criterion-related validation: a twostudy investigation. Journal of Managerial Psychology, 23, 744-771.

Ferris, G. R., Ellen III, B. P., McAllister, C. P., \& Maher, L. P. (2019). Reorganizing organizational politics research: A review of the literature and identification of future research directions. Annual Review of Organizational Psychology and Organizational Behavior, 6, 299-323.

Ferris, G. R., Harris, J. N., Russell, Z. A., \& Maher, L. P. (2018). Politics in organizations. In D. S. Ones, N. R. Anderson, C. Viswesvaran, \& H. K. Sinangil (Eds.), The SAGE Handbook of Industrial, Work \& Organizational Psychology: Organizational Psychology (pp. 469-386). Los Angeles, USA: Sage.

Ferris, G. R., Treadway, D. C., Kolodinsky, R. W., Hochwarter, W. A., Kacmar, C. J., Douglas, C., \& Frink, D. D. (2005). Development and validation of the political skill inventory. Journal of Management, 31, 126-152. 
Ferris, G. R., Treadway, D. C., Perrewé, P. L., Brouer, R. L., Douglas, C., \& Lux, S. (2007). Political skill in organizations. Journal of Management, 33, 290-320.

Greenbaum, R. L., Mawritz, M. B., \& Quade, M. J. (2017). Employee Machiavellianism to unethical behavior: the role of abusive supervision as a trait activator. Journal of Management, 43, 585-609.

Harris, K. J., Kacmar, K. M., Zivnuska, S., \& Shaw, J. D. (2007). The impact of political skill on impression management effectiveness. Journal of Applied Psychology, 92, 278 285.

Harvey, P., Harris, K. J., Kacmar, K. M., Buckless, A., \& Pescosolido, A. T. (2014). The impact of political skill on employees' perceptions of ethical leadership. Journal of Leadership \& Organizational Studies, 21, 5-16.

Hayes, A. F. (2015). An index and test of linear moderated mediation. Multivariate Behavioral Research, 50, 1-22.

Hirschfeld, R. R., \& Van Scotter, J., II. (2019). Vocational behavior from the dark side. Journal of Vocational Behavior, 110 (Part B), 303-316.

Hogan, J., Barrett, P., \& Hogan, R. (2007). Personality measurement, faking, and employment selection. Journal of Applied Psychology, 93, 1270-1285.

Hogan, J., Hogan, R., \& Kaiser, R. B. (2011). Management derailment. In S. Zedeck (Ed.), APA Handbook of industrial and organizational psychology, Vol. 3 (pp. 555-576). Washington, DC: APA.

Hogan, R., \& Blake, R. (1999). John Holland's vocational typology and personality theory. Journal of Vocational Behavior, 55, 41-56.

Hogan, R., \& Blickle, G. (2013). Socioanalytic theory. In N. D. Christiansen \& R. P. Tett (Eds.), Handbook of Personality at Work (pp. 53-70). New York, NY: Routledge / Taylor and Francis.

Hogan, R., \& Blickle, G. (2018). Socioanalytic Theory: Basic concepts, supporting evidences, 
and practical implications. In V. Zeigler-Hill, \& T. K. Shackelford (Eds.), The SAGE Handbook of Personality and Individual Differences (pp. 110-129). Thousand Oaks, CA: SAGE.

Hogan, R., \& Shelton, D. (1998). A socioanalytic perspective on job performance. Human Performance, 11, 129-144.

Inkson, K. (2004). Images of career: Nine key metaphors. Journal of Vocational Behavior, $65,96-111$.

Jacobson, R. K., \& Viswesvaran, C. (2017). A reliability generalization study of the political skill inventory. SAGE Open, 7, 1-17.

Johnson, J. A., \& Hogan, R. (2006). A socioanalytic view of faking. In R. Griffith \& H. M. Peterson (Eds.), A closer examination of applicant faking (pp. 207-229). Greenwich, CT: Information Age.

Jones, D. N. (2014). Predatory personalities as behavioral mimics and parasites: MimicyDeception Theory. Perspective on Psychological Science, 9, 445-451.

Kish-Gephart, J. J., Harrison, D. A., \& Trevino, L. K. (2010). Bad apples, bad cases, and bad barrels: meta-analytic evidence about sources of unethical decisions at work. Journal of Applied Psychology, 95, 1-31.

LeBreton, J. M., \& Senter, J. (2008). Answers to 20 questions about interrater reliability and interrater agreement. Organizational Research Methods, 11, 815-852.

Lilienfeld, S. O., \& Widows, M. R. (2005). Psychological assessment inventory-revised (PPIR). Lutz, FL: Psychological Assessment Resources.

Liu, C. C. (2008). The relationship between Machiavellianism and knowledge sharing willingness. Journal of Business Psychology, 22, 233-240.

Lvina, E., Johns, G., Treadway, D. C., Blickle, G., Liu, Y., Liu, J., Atay, S., Zettler, I., Solga, J., Noethen, D., \& Ferris, G. R. (2012). Measure invariance of the Political Skill 
Inventory (PSI) across five cultures. International Journal of Cross-Cultural Management, 12, 171-191.

Machiavelli, N. (1950). The prince. Ney York, NY: Modern Library (Original work published 1532).

Mackey, J. D., McAllister, C. P., Maher, L. P., \& Wang, G. (2019). Leaders and followers behaving badly: A meta-analytic examination of curvilinear relationships between destructive leadership and followers' workplace behaviors. Personnel Psychology, 72, $3-47$.

Maher, L. P., Gallagher, V. C., Rossi, A. M., Ferris, G. R., \& Perrewé, P. L. (2018). Political skill and will as predictors of impression management frequency and style: A threestudy investigation. Journal of Vocational Behavior, 107, 276-294.

McAllister, C. P., Ellen, B. P., \& Ferris, G. R. (2018). Social influence opportunity recognition, evaluation, and capitalization: Increased theoretical specification through political skill's dimensional dynamics. Journal of Management, 44, 1926-1952.

Mercado, B. K., Dilchert, S., Giordano, C., \& Ones, D. S. (2018). Counterproductive work behaviors. In D. S. Ones, N. R. Anderson, C. Viswesvaran, \& H. K. Sinangil (Eds.), The SAGE Handbook of Industrial, Work \& Organizational Psychology: Personnel Psychology and Employee Performance (pp. 109-211). Los Angeles, USA: Sage.

Meurs, J. A., Gallagher, V. C., \& Perrewé, P. L. (2010). The role of political skill in the stressor-outcome relationship: Differential predictions for self- and other-reports of political skill. Journal of Vocational Behavior, 76, 520-533.

Monaghan, C., Bizumic, B., \& Sellbom, M. (2018). Nomological network of two-dimensional Machiavellianism. Personality and Individual Differences, 130, 161-173.

Moshagen, M., Hilbig, B., \& Zettler, I. (2018). The dark core of personality. Psychological Review, 125, 656-688.

Mount, M., Ilies, R., \& Johnson, E. (2006). Relationship of personality traits and counterproductive work behaviors: the mediating effects of job satisfaction. Personnel 
Psychology, 59, 591-622.

Munyon, T. P., Summers, J. K., Thompson, K. M. \& Ferris, G. R. (2015). Political skill and work outcomes: a theoretical extension, meta-analytic investigation, and agenda for the future. Personnel Psychology, 68, 143-184.

Muthén, L. K., \& Muthén, B. O. (2012). Mplus user's guide (7th ed.). Los Angeles, CA: Muthén \& Muthén.

Ng, T. W. H., Eby, L., Sorensen, K. L., \& Feldman, D. C. (2005). Predictors of objective and subjective career success: A meta-analysis. Personnel Psychology, 58, 367-408.

Ng, T. W., \& Feldman. D. C. (2008). The relationship of age to ten dimensions of job performance. Journal of Applied Psychology, 93, 392-423.

O'Boyle Jr., E. H., Forsyth, D. R., Banks, G. C., \& McDaniel, M. A. (2012). A meta-analysis of the dark triad and work behavior: a social exchange perspective. Journal of Applied Psychology, 97, 557-579.

Owens, B. P., Wallace, A. S., \& Waldman, D. A. (2015). Leader narcissism and follower outcomes: the counterbalancing effect of leader humility. Journal of Applied Psychology, 100, 1203-1213.

Pan, W., Zhou, Y., \& Zhang, Q. (2016). Does darker hide more knowledge? The relationship between Machiavellianism and knowledge hiding. International Journal of Security and Its Applications, 10, 281-292.

Parker, S., Jimmieson, N., \& Amiot, C. (2009). The stress-buffering effect of control on task satisfaction and perceived goal attainment: An experimental study of the moderating influence of desire for control. Applied Psychology: An International Review, 58, 622658.

Paulhus, D. L., \& Williams, K. M. (2002). The Dark Triad of personality: Narcissism, Machiavellianism, and Psychopathy. Journal of Research in Personality, 36, 556-563.

Podsakoff, P. M., MacKenzie, S. B., \& Podsakoff, N. P. (2012). Sources of method bias in social science research and recommendations on how to control it. Annual Review of 
Psychology, 63, 539-569.

Rodriguez, R. A., \& Guest, D. (2010). Have careers become boundaryless? Human Relations, $63,1157-1175$.

Roth, C., Wegge, J., \& Schmidt, K.-H. (2007). Consequences of demographic change for the management of human resources in organizations. Journal of Personnel Psychology, $6,99-116$.

Sackett, P. R., \& Yang, H. (2000). Correction for range restriction: An expanded typology. Journal of Applied Psychology, 85, 112-118.

Schütte, N., Blickle, G., Frieder, R., Wihler, A., Schnitzler, F., Heupel, J., \& Zettler, I. (2018). The role of interpersonal influence in counterbalancing psychopathic personality trait facets at work. Journal of Management 44, 1338-1368.

Semadar, A., Robins, G., \& Ferris, G. R. (2006). Comparing the validity of multiple social effectiveness constructs in the prediction of managerial job performance. Journal of Organizational Behavior, 27, 443-461.

Stavrova, O., \& Ehlebracht, D. (2016). Cynical beliefs about human nature and income: Longitudinal and cross-cultural analyses. Journal of Personality and Social Psychology, 110, 116-132.

Stavrova, O., \& Ehlebracht, D. (2019). The cynical genius illusion: Exploring and debunking lay beliefs about cynicism and competence. Personality and Social Psychology Bulletin, 45, 254-269.

Stieglitz, R.-D. (2003) Triangulation. In R. Fernandez-Ballesteros (Ed.). Encyclopedia of Psychological Assessment (Vol 2, pp. 608-610). London: Sage.

Tabachnick, B. G., \& Fidell, L. S. (2013). Using multivariate statistics (6th ed.). Boston, Mass.: Pearson. 
Templer, K.J. (2018). Dark personality, job performance ratings, and the role of political skill: An indication of why toxic people may get ahead at work. Personality and Individual Differences, 124, 209-214.

Treadway, D. C., Shaugnessy, B. A., Breland, J. W., Yang, J., \& Reeves, M. (2013). Political skill and the job performance of bullies. Journal of Managerial Psychology, 28, 273289.

Van Vugt, M., Hogan, R., \& Kaiser, R. B. (2008). Leadership, followership, and evolution: Some lessons from the past. American Psychologist, 63, 182-196.

Waldman, D. A., \& Avolio, B. J. (1986). A meta-analysis of age differences in job performance. Journal of Applied Psychology, 71, 33-38.

Weiss, B. M. et al. (2019). Examining hypothesized interactive and curvilinear relations between psychopathic traits and externalizing problems in an offender sample using item response-based analysis. Journal of Abnormal Psychology, 128, 689-699.

Welbourne, T. M., Johnson, D. E., \& Erez, A. (1998). The role-based performance scale: validity analysis of a theory-based measure. Academy of Management Journal, 41, $540-555$.

Wiernik, B. M., \& Wille, B. (2018). Careers, career development and career management. In D. S. Ones, N. Anderson, C. Viswesvaran, \& H. K. Sinangil (Eds.), The Sage handbook of Industrial, Work and Organizational Psychology: Managerial Psychology and Organizational approaches (pp. 547-585). Los Angeles: Sage.

Zacher, H. (2015). Daily manifestations of career adaptability: Relationships with job and career outcomes. Journal of Vocational Behavior, 91, 76-86.

Zettler, I., \& Hilbig, B.E. (2010). Honesty-humility and a person-situation interaction at work. European Journal of Personality, 24, 569-582.

Zettler, I., Kramer, J., Thoemmes, F., Nagy, G., \& Trautwein, U. (2013). Different types of universities and early career success: An exploratory investigation [Welchen Einfluss 
hat der Besuch unterschiedlicher Hochschultypen auf den frühen beruflichen Erfolg? Eine explorative Untersuchung]. Zeitschrift für Pädagogische Psychologie, 27, 51-62.

Zettler, I., \& Solga, M. (2013). Not enough of a 'dark' trait? Linking Machiavellianism to job performance. European Journal of Personality, 27, 545-554.

Zinko, R., Ferris, G. R., Blass, F. R., \& Laird, M. D. (2007). Toward a theory of reputation in organizations. In J. J. Martocchio (Ed.), Research in personnel and human resources management, Vol. 26 (pp. 163-204). Oxford, UK: Elsevier. 
Table 1a

Means, Standard Deviations, Correlations and Cronbach's Alpha Values of the Variables in Sample 1

\begin{tabular}{llrrrrrrr}
\hline & & $M$ & $S D$ & 1 & 2 & 3 & 4 & 5 \\
\hline 1 & Age & 43.01 & 12.37 & - & & & & \\
2 & MACH & 2.05 & 0.46 & -.11 & $(.84)$ & & & \\
3 & PS & 5.02 & 0.71 & .00 & .08 & $(.89)$ & & \\
4 & Tenure & 10.74 & 9.27 & $.60^{*}$ & -.05 & -.09 & - & \\
5 & CRP & 3.70 & 0.64 & -.05 & -.07 & $.27^{*}$ & -.11 & $(.87)$ \\
\hline
\end{tabular}

Note. $N=251 \mathrm{MACH}=$ Machiavellianism, $\mathrm{PS}=$ political skill, Tenure $=$ job tenure in years, $\mathrm{CRP}=$ Career role performance.

${ }^{*} p<.05$.

Table $1 \mathrm{~b}$

Means, Standard Deviations, Correlations and Cronbach's Alpha Values of the Variables in Sample 2

\begin{tabular}{llrrrrrrrr}
\hline & & $M$ & $S D$ & 1 & 2 & 3 & 4 & 5 & 6 \\
\hline 1 & Age & 39.68 & 12.80 & - & & & & & \\
2 & MACH & 2.24 & 0.57 & $-.20^{*}$ & $(.87)$ & & & & \\
3 & PS & 4.99 & 0.81 & .03 & .02 & $(.90)$ & & & \\
4 & Tenure & 9.46 & 9.46 & $.63^{*}$ & $-.14^{*}$ & .01 & - & & \\
5 & CWB-I & 1.75 & 0.85 & $-.16^{*}$ & $.39^{*}$ & $-.17^{*}$ & -.06 & $(.84)$ & \\
6 & CWB-O & 1.83 & 0.74 & $-.24^{*}$ & $.32^{*}$ & $-.14^{*}$ & $-.16^{*}$ & $.61 *$ & $(.83)$ \\
\hline
\end{tabular}

Note. $N=685, \mathrm{MACH}=$ Machiavellianism, $\mathrm{PS}=$ political skill, Tenure $=$ job tenure in years, $\mathrm{CWB}-$ $\mathrm{I}=$ Interpersonally-directed counterproductive work behavior, CWB-O $=$ Counterproductive work behavior directed toward the organization.

${ }^{*} p<.05$. 
Table 2

Hierarchical Moderated Regression Analysis for Career Role Performance in Sample 1

\begin{tabular}{|c|c|c|c|c|c|c|}
\hline & \multicolumn{2}{|c|}{ Model 1a } & \multicolumn{2}{|c|}{ Model 1b } & \multicolumn{2}{|c|}{ Model 1c } \\
\hline Predictors & $B(S E)$ & $\beta$ & $B(S E)$ & $\beta$ & $B(S E)$ & $\beta$ \\
\hline Age & $-.00(.05)$ & -.00 & $.01(.05)$ & .01 & $.00(.05)$ & .00 \\
\hline MACH & $-.06(.04)$ & -.10 & $-.05(.04)$ & -.08 & $-.05(.04)$ & -.08 \\
\hline PS & $.17(.04)$ & $.27 *$ & $.17(.04)$ & $.27 *$ & $.16(.04)$ & $.26^{*}$ \\
\hline Tenure & $-.06(.05)$ & -.09 & $-.06(.04)$ & -.09 & $-.06(.05)$ & -.10 \\
\hline MACHxPS & & & $.07(.04)$ & $.13 *$ & $.09(.04)$ & $.16^{*}$ \\
\hline MACHxTenure & & & $-.01(.04)$ & -.02 & $-.01(.04)$ & -.02 \\
\hline PSxTenure & & & $.02(.04)$ & .02 & $.01(.04)$ & .02 \\
\hline MACHxPSxTenure & & & & & $.10(.04)$ & $.14^{*}$ \\
\hline$R^{2}$ & & $.088 *$ & & $105^{*}$ & & $.124 *$ \\
\hline$F_{R^{2}}(d f 1, d f 2)$ & & 246) & & 243) & & $4.30(8,242$ \\
\hline$\Delta R^{2}$ & & & & .017 & & $.019^{*}$ \\
\hline$F_{\Delta R^{2}}(d f 1, d f 2)$ & & & & 243) & & $5.25(1,242$ \\
\hline
\end{tabular}

Note. $N=251 ;$ Tenure $=$ job tenure in years, $\mathrm{MACH}=$ Machiavellianism, $\mathrm{PS}=$ political skill. $* p<.05$. 
Table 3

Hierarchical Moderated Regression Analysis for Counterproductive Work Behavior Directed Against the Organization and Interpersonally-Directed Counterproductive Work Behavior in Sample 2

\begin{tabular}{|c|c|c|c|c|c|c|c|c|c|c|c|c|}
\hline \multirow[b]{3}{*}{ Predictors } & \multicolumn{6}{|c|}{ CWB-I } & \multicolumn{6}{|c|}{ CWB-O } \\
\hline & \multicolumn{2}{|c|}{ Model 2a } & \multicolumn{2}{|c|}{ Model 2b } & \multicolumn{2}{|c|}{ Model 2c } & \multicolumn{2}{|c|}{ Model 3a } & \multicolumn{2}{|c|}{ Model 3b } & \multicolumn{2}{|c|}{ Model 3c } \\
\hline & $\beta$ & $B(S E)$ & $\beta$ & $B(S E)$ & $\beta$ & $B(S E)$ & $\beta$ & $B(S E)$ & $\beta$ & $B(S E)$ & $\beta$ & $B(S E)$ \\
\hline Age & $-.13 *$ & $-.12(.04)$ & $-.14 *$ & $-.12(.04)$ & $-.14 *$ & $-.12(.04)$ & $-.17 *$ & $-.13(.03)$ & $-.17 *$ & $-.13(.03)$ & $-.17 *$ & $-.13(.04)$ \\
\hline $\mathrm{MACH}$ & $.38 *$ & $.30(.03)$ & $.35 *$ & $.30(.03)$ & $.36 *$ & $.30(.03)$ & $.29 *$ & $.21(.03)$ & $.29 *$ & $.22(.03)$ & $.29 *$ & $.22(.03)$ \\
\hline PS & $-.17 *$ & $-.17(.04)$ & $-.20 *$ & $-.16(.04)$ & $-.19 *$ & $-.16(.04)$ & $-.14 *$ & $-.10(.03)$ & $-.18 *$ & $-.13(.03)$ & $-.16^{*}$ & $-.12(.03)$ \\
\hline Tenure & .07 & $.12(.06)$ & $.14 *$ & $.13(.06)$ & $.15^{*}$ & $.13(.06)$ & -.01 & $-.01(.03)$ & .04 & $.03(.05)$ & .05 & $.03(.05)$ \\
\hline MACHхMACH & & & $.11 *$ & $.07(.02)$ & $.11^{*}$ & $.07(.02)$ & & & .00 & $.00(.02)$ & .01 & $.01(.02)$ \\
\hline PSxPS & & & -.02 & $-.00(.02)$ & -.01 & $-.00(.02)$ & & & -.02 & $-.01(.02)$ & -.01 & $-.00(.02)$ \\
\hline TenurexTenure & & & -.09 & $-.04(.03)$ & -.09 & $-.04(.03)$ & & & -.08 & $-.04(.02)$ & -.07 & $-.03(.02)$ \\
\hline MACHxPS & & & $-.10 *$ & $-.08(.03)$ & $-.11 *$ & $-.08(.03)$ & & & $-.10 *$ & $-.07(.03)$ & $-.11 *$ & $-.07(03)$ \\
\hline MACHxTenure & & & .01 & $.01(.03)$ & .01 & $.01(.03)$ & & & -.03 & $-.02(.03)$ & -.02 & $-.02(.03)$ \\
\hline PSxTenure & & & -.03 & $.05(.04)$ & .06 & $.05(.04)$ & & & .02 & $.02(.03)$ & $.10 *$ & $.08(.03)$ \\
\hline MACHxMACHxPS & & & .06 & $.01(.02)$ & .02 & $.01(.02)$ & & & .06 & $.02(.02)$ & .02 & $.01(.02)$ \\
\hline MACHxMACHxTenure & & & .02 & $-.00(.03)$ & -.00 & $-.00(.03)$ & & & .02 & $.01(.02)$ & .00 & $.00(.02)$ \\
\hline MACHxPSxTenure & & & & & .02 & $.02(.03)$ & & & & & .02 & $.02(.03)$ \\
\hline MACHxMACHxPSxTenure & & & & & $-.16^{*}$ & $-.07(.02)$ & & & & & $-.17 *$ & $-.07(.02)$ \\
\hline$R^{2}$ & & $.190^{*}$ & & $.213^{*}$ & & $.225 *$ & & $.154^{*}$ & & $.167 *$ & & $.180^{*}$ \\
\hline$F_{R^{2}}(d f 1, d f 2)$ & & $98(4,680)$ & 15 . & $17(12,672)$ & 13.8 & $7(14,670)$ & & $.90(4,680)$ & 11. & $5(12,672)$ & 10.5 & $3(14,670)$ \\
\hline & & & & $.023^{*}$ & & $.012 *$ & & & & .013 & & $.013^{*}$ \\
\hline$F_{\Delta R^{2}}(d f 1, d f 2)$ & & & & $.43(8,672)$ & & $98(2,670)$ & & & & $36(8,672)$ & & $35(2,670)$ \\
\hline
\end{tabular}

Note. $N=685$; Tenure $=$ job tenure in years, CWB-I $=$ Interpersonally-directed counterproductive work behavior, $\mathrm{CWB}-\mathrm{O}=\mathrm{Counterproductive} \mathrm{work} \mathrm{behavior} \mathrm{directed}$ towards the organization, $\mathrm{MACH}=$ Machiavellianism, $\mathrm{PS}=$ Political skill.

$* p<.05$. 


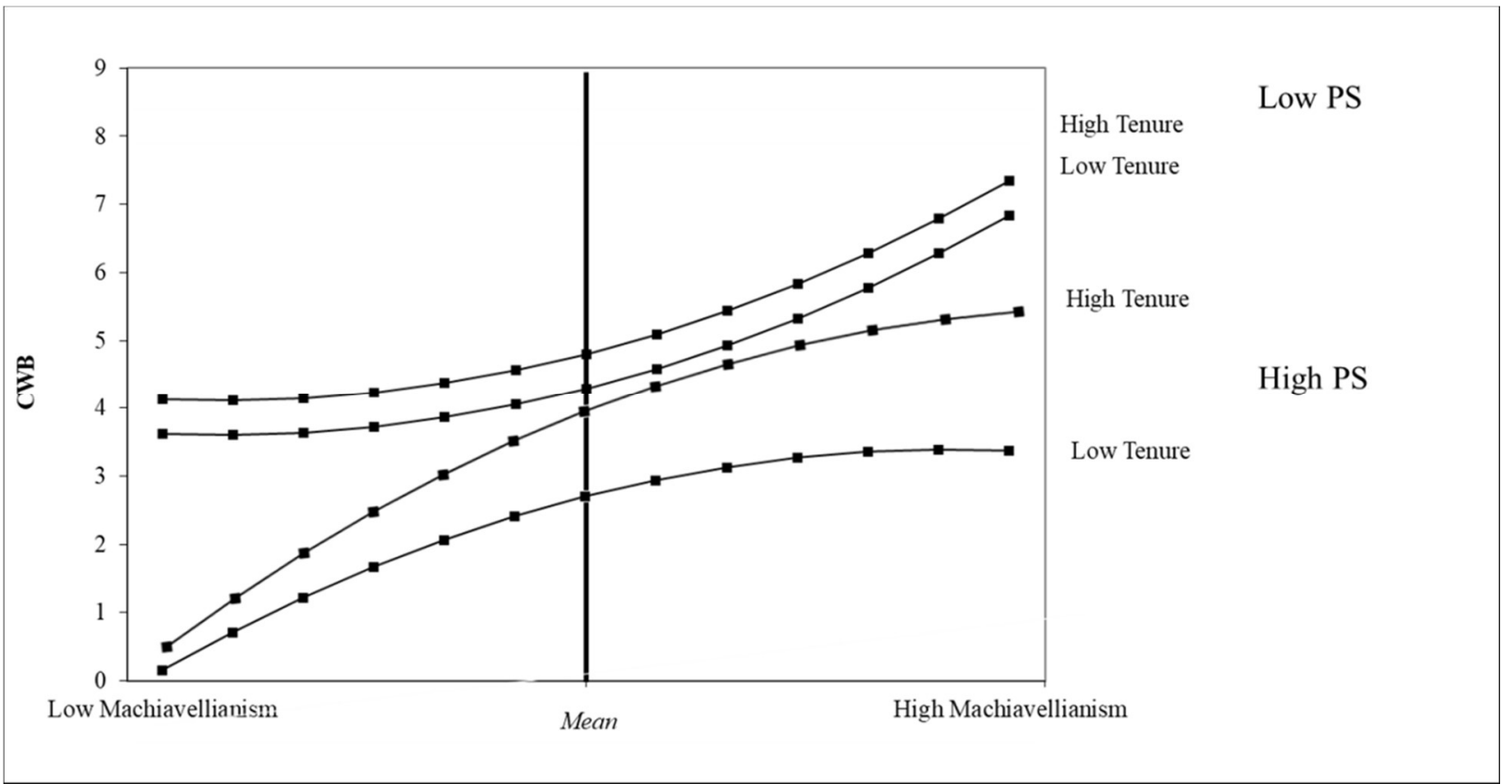

Figure 1. Hypotheses 2 and $3(\mathrm{CWB}=$ counterproductive work behavior, $\mathrm{PS}=$ Political Skill). 


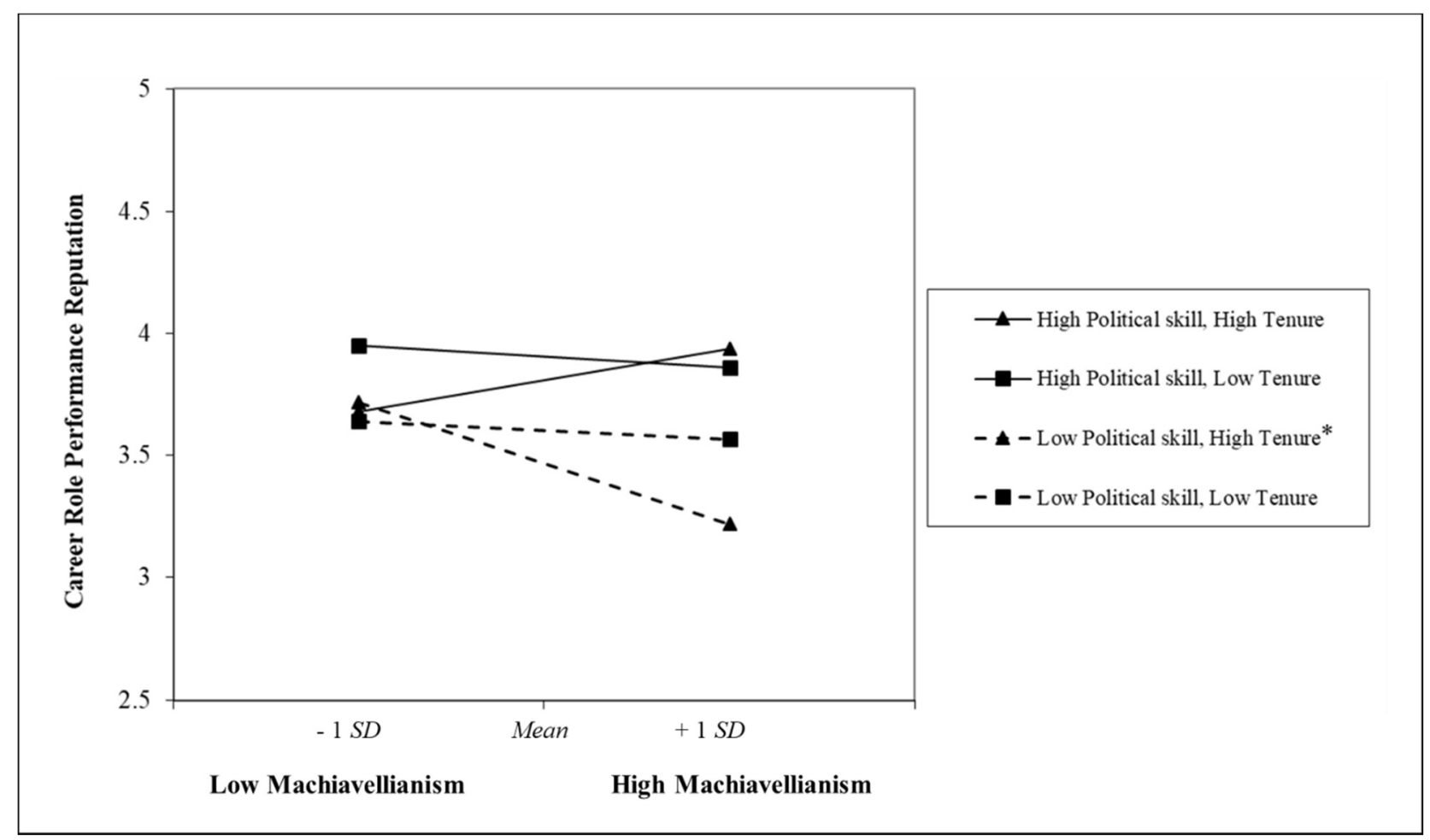

Figure 2a. Relations between Machiavellianism (+/- $1 S D)$ and career role performance assessed by coworkers and moderated by employees' political skill and tenure (negative slope of low political skill and high tenure, $\left.{ }^{*} p<.05\right)$.

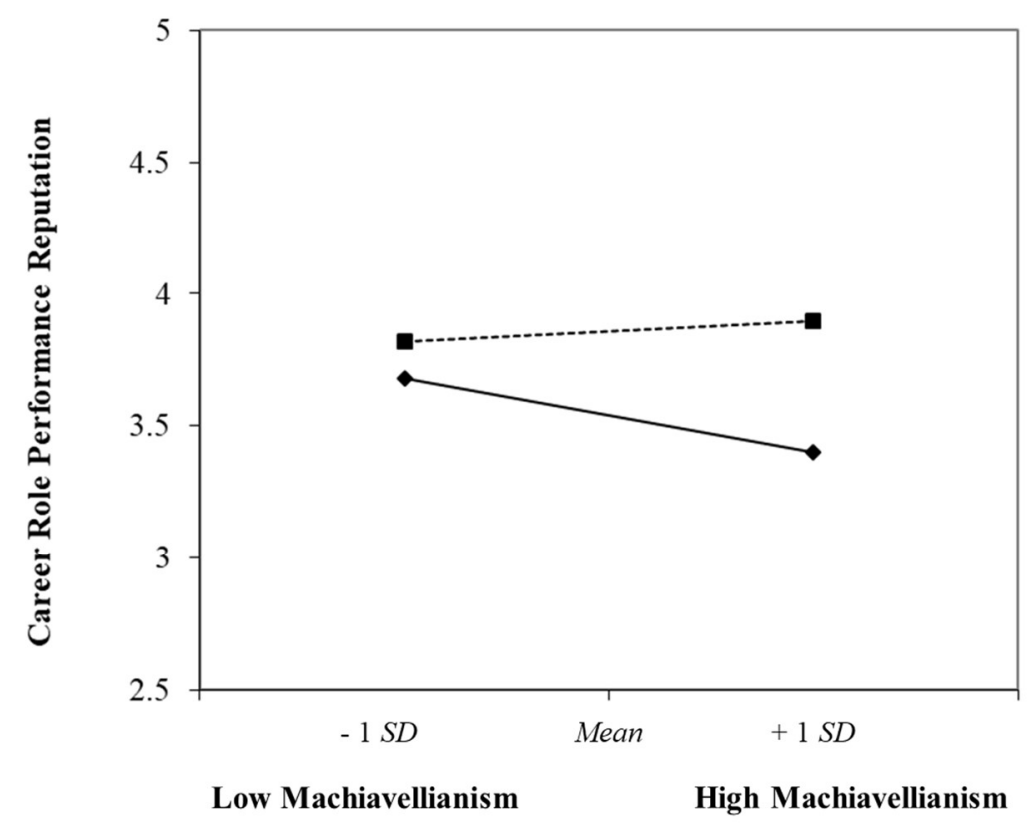

Figure 2b. Relations between Machiavellianism (+/- $1 S D)$ and career role performance assessed by coworkers and moderated by employees' political skill (negative slope for low political skill and high tenure, $\left.{ }^{*} p<.05\right)$. 


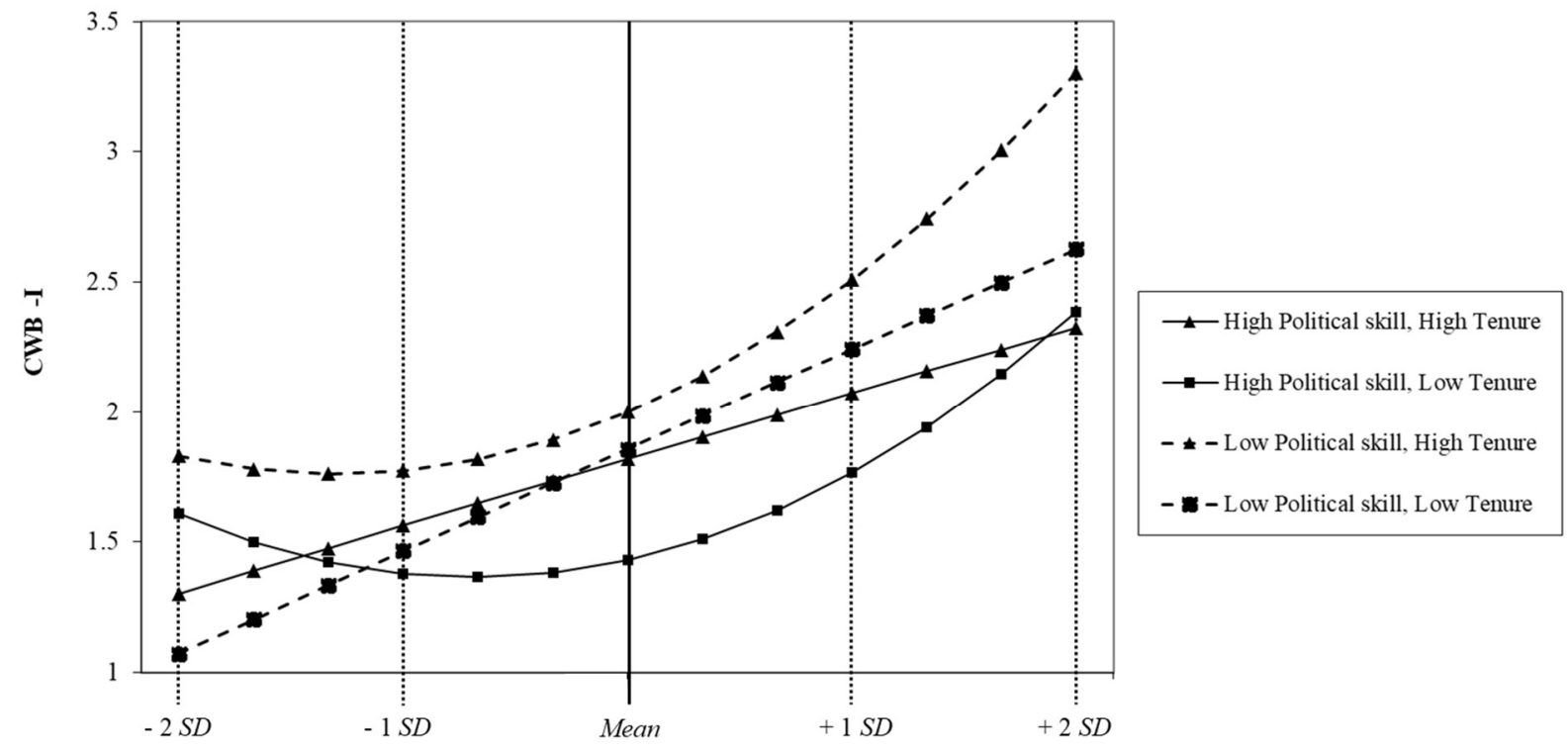

Low Machiavellianism High Machiavellianism

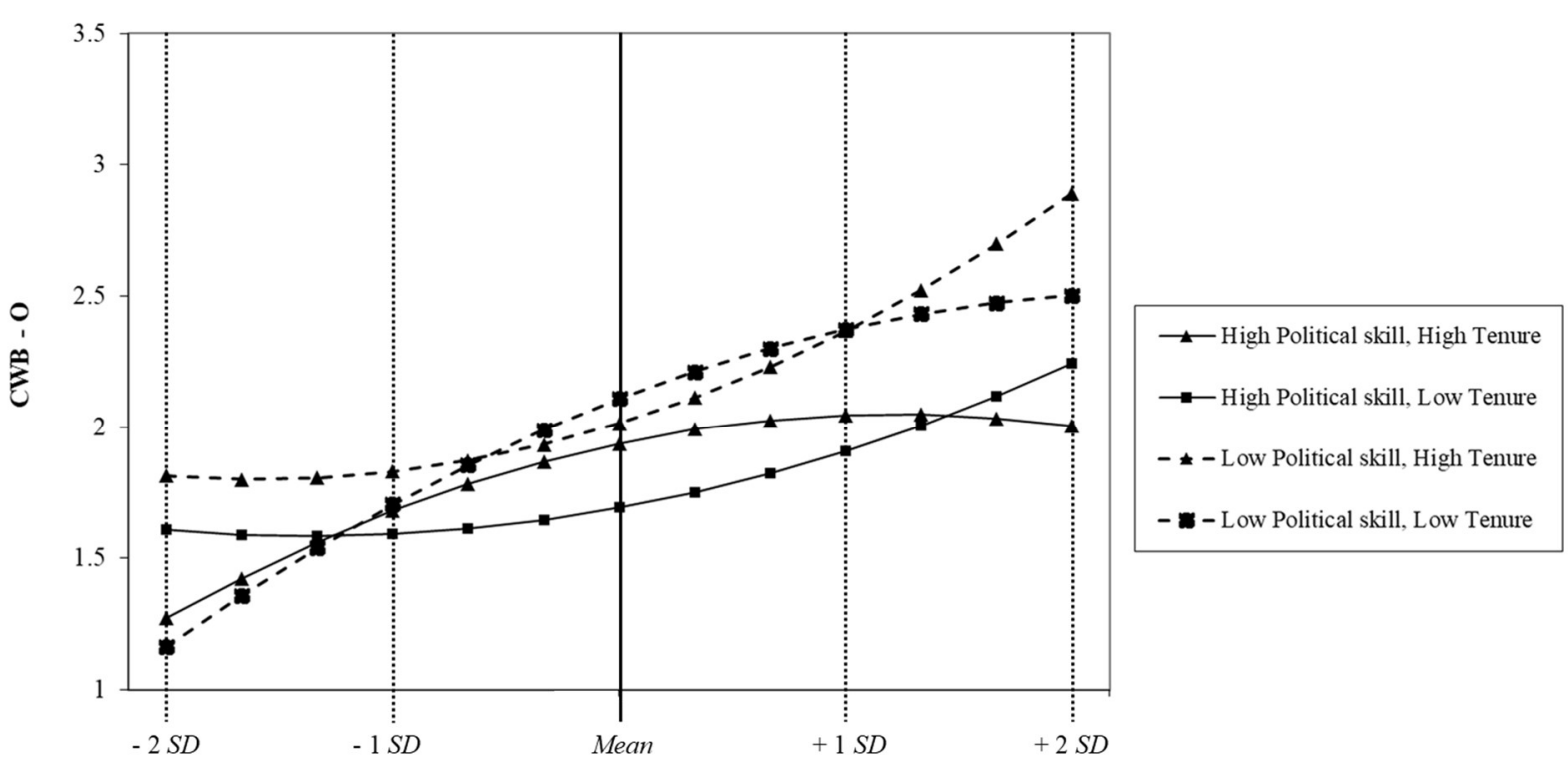

Low Machiavellianism

High Machiavellianism

Figure 3. Relations between Machiavellianism and CWB-O/CWB-I, moderated by political skill and tenure. 


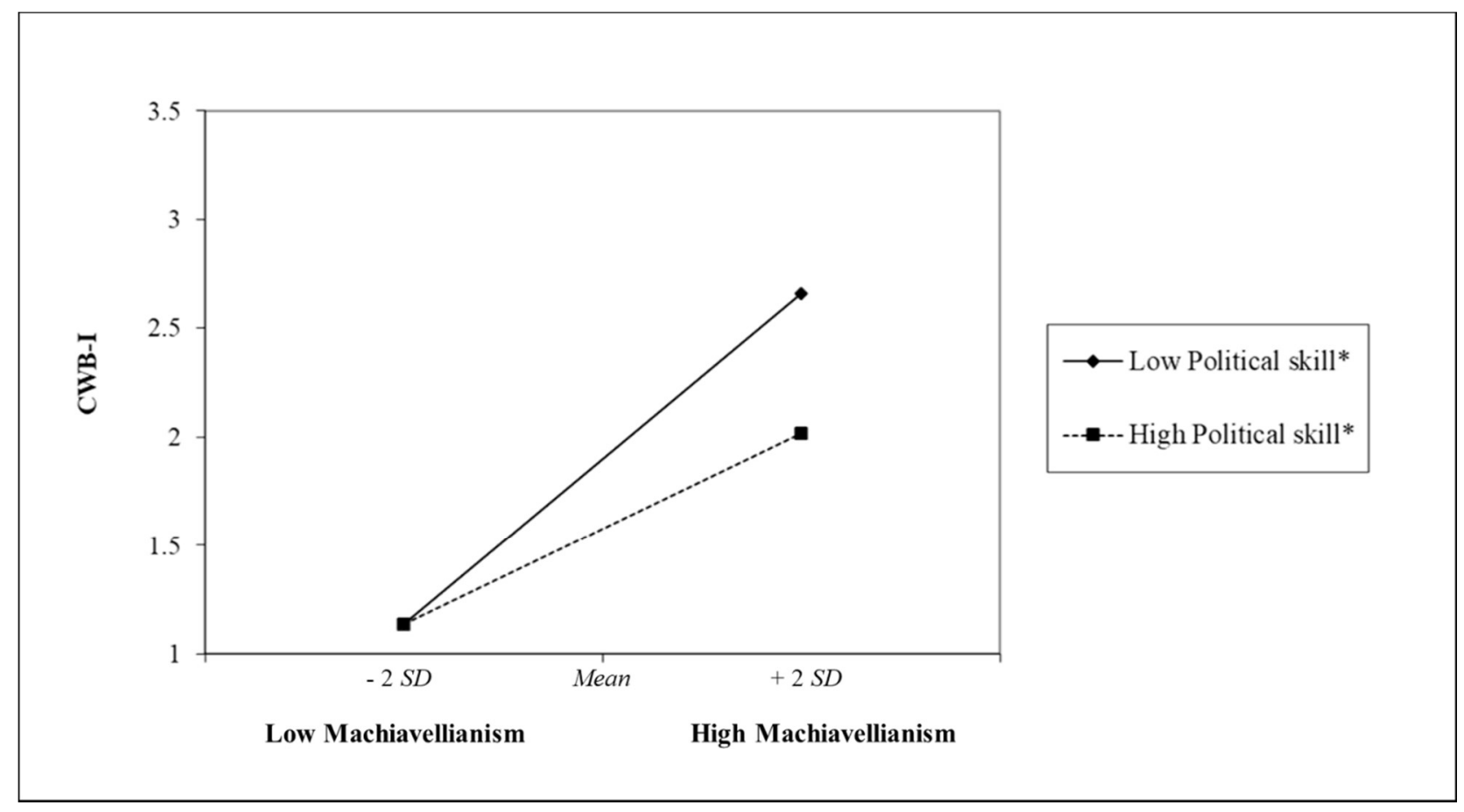

Figure 4a. Relations between Machiavellianism (+/- $2 S D)$ and anonymously self-reported CWB-I moderated by employees' political skill (positive slopes for MACH, ${ }^{*} p<.05$ ).

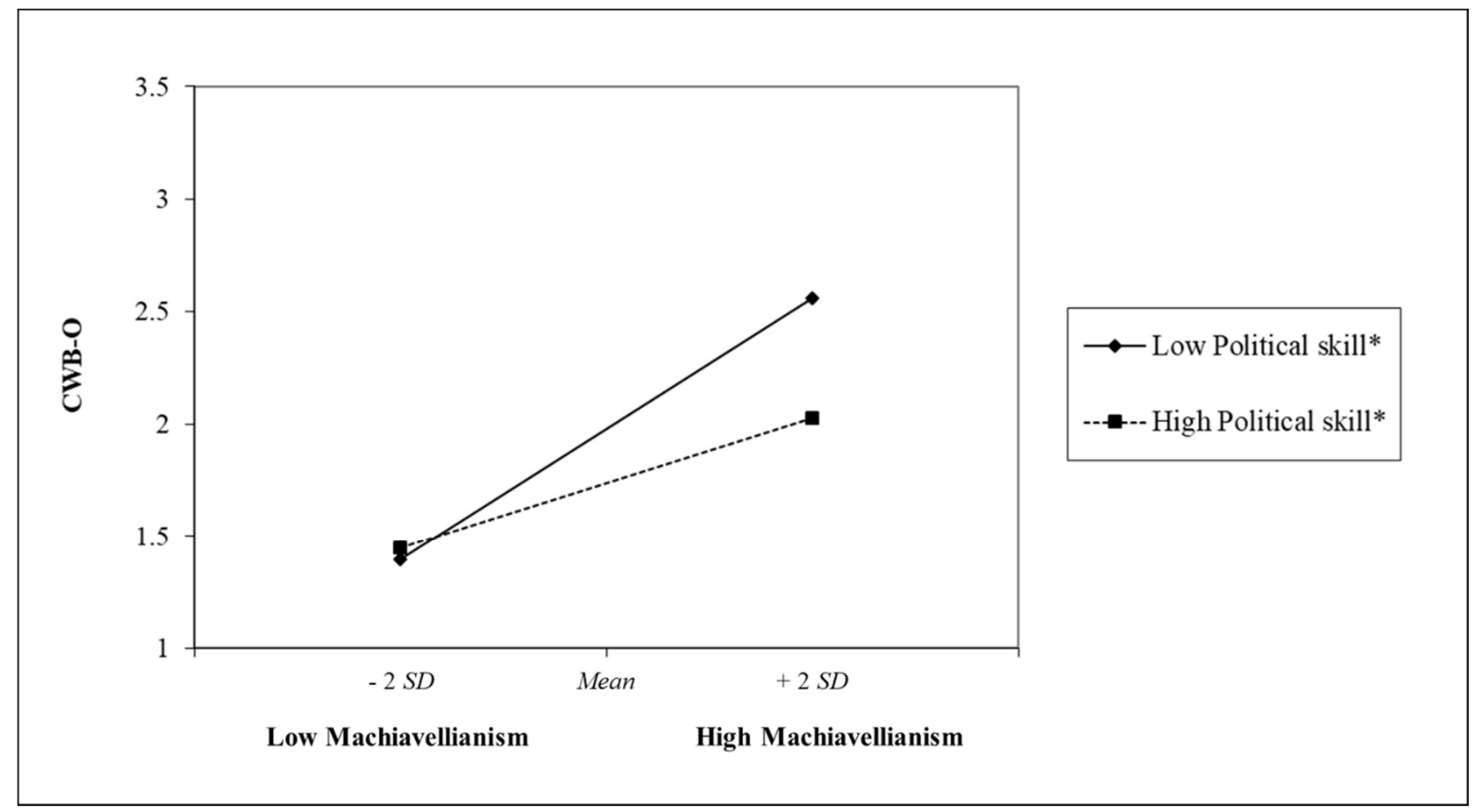

Figure $4 b$. Relations between Machiavellianism (+/- $2 S D$ ) and anonymously self-reported CWB-O moderated by employees' political skill (positive slopes for MACH, ${ }^{*} p<.05$ ). 


\begin{abstract}
APPENDIX
Political Skill Camouflages Machiavellianism: Career Role Performance and Organizational Misbehavior at Short and Long Tenure
\end{abstract}

\title{
1. Discriminant validity of the CRP scale with reference to proactivity
}

To assess the discriminant validity of the CRP scale with reference to proactivity (e.g., "This person actively attacks problems"; Fay \& Frese, 2001), we conducted a validation study. Participants were recruited on a British crowdsourcing site for academic research named Prolific. We asked employees to think of and select one of their colleagues with whom they had been working for 2 years or longer. The instructions said: "You should work closely with this person and know him or her best at work." Employees rated this colleague with reference to a workplace proactivity scale ("This person often tries to adopt improved procedures for doing his or her job"; Morrison \& Phelps, 1999), personal initiative ("This person takes initiative immediately even when others don't"; Fay \& Frese, 2001), career goal progress ("In his/her job, this person moves closer to his/her career goals"; Weng, McElroy, Morrow, \& Liu, 2010), career-related skills (“This person seeks out opportunities for continuous learning in his/her career"; Eby, Butts, Lockwood, 2003), and the CRP, job role performance (“Quantity of work output"), innovator role performance (“Coming up with new ideas," and team role performances ("Responding to the needs of others in his/her work group") scales (Welbourne et al., 1998).

Schönbrodt and Perugini (2013) determined that correlation estimates stabilize at a sample size of $N \approx 250$. Therefore, we tried to sample at least 250 study participants. In all, 306 individuals completed the questionnaire; 6 failed an attention check, 45 employees were removed because they had work-related contact with the appraisee less than once a week $(N=$ 11) or because the time they had been collaborating with the appraisee at work was less than 2 
years $(N=35)$, or both, resulting in a final sample of 255 employees $\left(M_{\text {age }}=34,11, S D_{\text {age }}=\right.$ $9.34,35.7 \%$ male).

Appendix Table 1

Convergent and Discriminant Correlations for Career Role Performance

\begin{tabular}{|c|c|c|c|c|c|c|c|c|c|}
\hline & & 1 & 2 & 3 & 4 & 5 & 6 & 7 & 8 \\
\hline 1 & $\mathrm{TC}$ & $\begin{array}{c}(.62) \\
(.92)^{(1)}\end{array}$ & $.28^{*}$ & -.07 & -.00 & -.20 & $.50^{*}$ & .12 & -.04 \\
\hline 2 & PI & $.79 *$ & $(.90)^{(.41)}$ & .12 & .18 & .03 & $.32 *$ & .13 & .20 \\
\hline 3 & Progress & $.53 *$ & $.62 *$ & $\begin{array}{l}(.71) \\
(.91)\end{array}$ & $.46^{*}$ & $-.27^{*}$ & -.07 & $.65^{*}$ & -.15 \\
\hline 4 & Skills & $.62 *$ & $.73 *$ & $.70 *$ & $(.88)^{(.52)}$ & -.20 & .03 & $.57^{*}$ & -.02 \\
\hline 5 & Job & $.61 *$ & $.73^{*}$ & $.48^{*}$ & $.60 *$ & $\begin{array}{l}(.42) \\
(.87)\end{array}$ & .06 & -.05 & $.61^{*}$ \\
\hline 6 & Innovator & $.80^{*}$ & $.79^{*}$ & $.54^{*}$ & $.68^{*}$ & $.74 *$ & $\begin{array}{l}(.31) \\
(.90)\end{array}$ & .44 & .24 \\
\hline 7 & CRP & $.59^{*}$ & $.66^{*}$ & $.75^{*}$ & $.75^{*}$ & $.57 *$ & $.69^{*}$ & $(.90)^{(.67)}$ & .12 \\
\hline 8 & Team & $.62 *$ & $.73 *$ & $.48^{*}$ & $.64^{*}$ & $.81 *$ & $.76^{*}$ & $.61^{*}$ & $\begin{array}{c}(.49) \\
(.89) \\
\end{array}$ \\
\hline
\end{tabular}

Note. $N=255, * p<.05$, relations between manifest variables below and relations between latent constructs above the diagonal; Cronbach's alpha (lower value) and McDonald's omega (upper value) in parentheses on the diagonal. $\mathrm{TC}=$ Taking Charge, $\mathrm{PI}=$ Personal Initiative, Progress $=$ Career Goal Progress, Skills $=$ Career-Related Skills, Job $=$ Job Role Performance, Innovator $=$ Innovator Role Performance, $\mathrm{CRP}=$ Career Role Performance, Team $=$ Team Role Performance.

The zero-order correlations of the CRP scale with the career goal progress scale and with the career-related skills scale were both $r=.75(p<.05)$; the zero-order correlation of the CRP scale with the workplace proactivity scale was $r=.59(p<.05)$; the differences between these correlations were significant $(z \geq 4.21, p<.05)$. The zero-order correlation of the CRP scale with the personal initiative scale was $r=.65(p<.05)$; the differences between this correlation and the correlation of the CRP scale with the career progress scale/careerrelated skills scale were also significant $(z \geq 2.58, p<.05)$. This confirmed the discriminant validity of the CRP scale with reference to proactive behavior at work and personal initiative.

To remove the common source and common measurement occasion bias (Podsakoff, MacKenzie, \& Podsakoff, 2012), we analyzed the data with a bifactor model (Reise, 2012) 
comprising one orthogonal common rater factor and eight correlated scale factors. Three scales attained an Omega reliability (McDonald, 1999) above .60: the workplace proactivity scale $(\Omega=.62$, Morrison \& Phelps, 1999$)$, the career goal progress scale $(\Omega=.71$, Weng et al., 2010), and the CRP scale $(\Omega=.67$, Welbourne et al., 1998). The correlations between these three scale factors also confirmed the discriminant validity of the CRP scale: The CRP scale factor was correlated with the career goal progress scale factor at rho $=.65(p<.05)$ and with the workplace proactivity scale factor at rho $=.12(p>.05)$, and the difference between these correlations was significant $(z=6.89, p<.05)$. In sum, this validation study confirmed the discriminant validity of the CRP scale with reference to proactive behavior at work. 


\section{Analyses in Study 1 without Control Variable (Table 2a) and Age and Tenure} reversed (Table 2b)

Appendix Table 2a

Hierarchical Moderated Regression Analysis for Career Role Performance in Sample 1without Control Variable

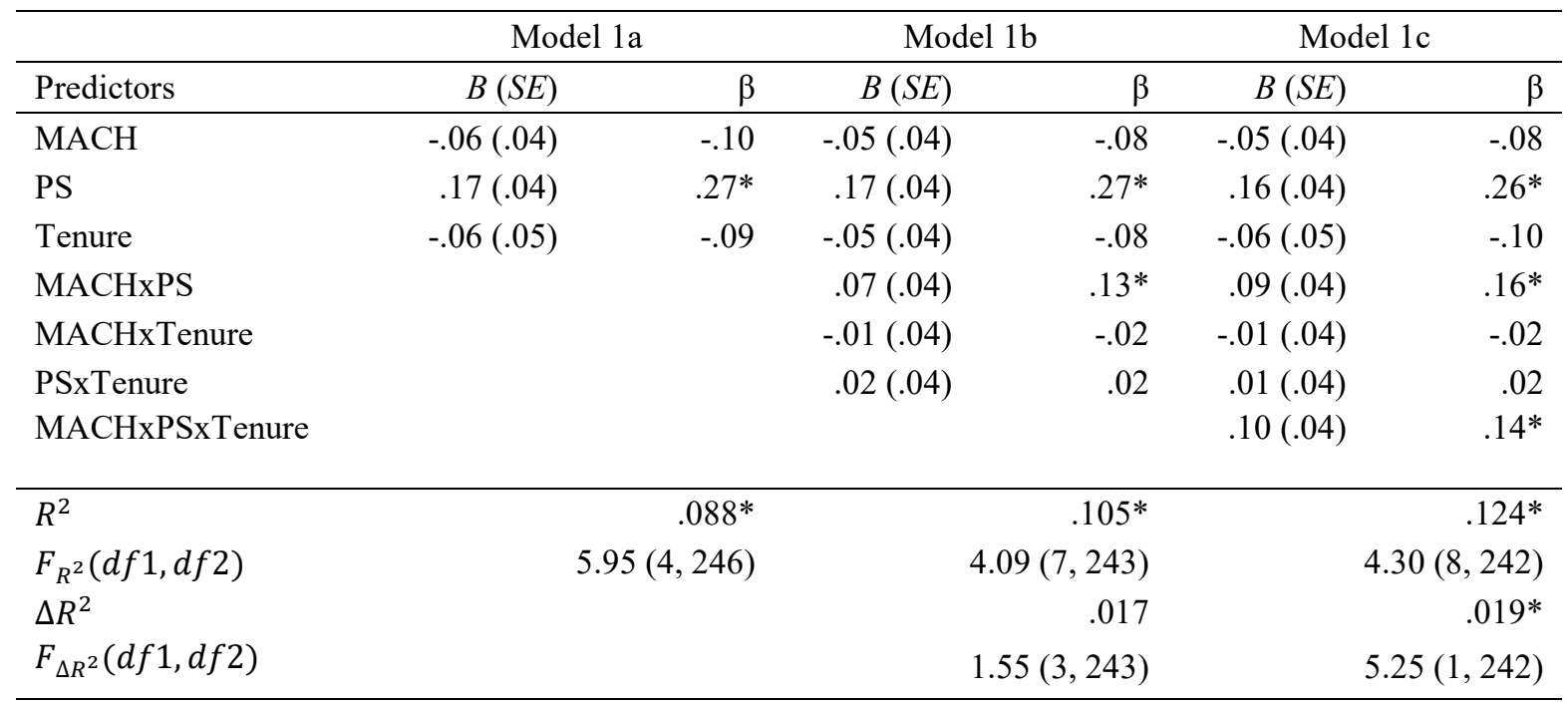

Note. $N=251 ;$ Tenure $=$ job tenure in years, $\mathrm{MACH}=$ Machiavellianism, $\mathrm{PS}=$ political skill. ${ }^{*} p<.05$.

Appendix Table 2b

Hierarchical Moderated Regression Analysis for Career Role Performance in Sample 1with reversed Roles (Tenure $=$ Control Variable and Age $=$ Moderator Variable)

\begin{tabular}{|c|c|c|c|c|c|c|}
\hline & \multicolumn{2}{|c|}{ Model 1a } & \multicolumn{2}{|c|}{ Model 1b } & \multicolumn{2}{|c|}{ Model 1c } \\
\hline Predictors & $B(S E)$ & $\beta$ & $B(S E)$ & $\beta$ & $B(S E)$ & $\beta$ \\
\hline Tenure & $-.06(.05)$ & -.09 & $-.05(.05)$ & -.08 & $-.05(.05)$ & -.08 \\
\hline MACH & $-.06(.04)$ & -.10 & $-.05(.04)$ & -.07 & $-.05(.04)$ & -.07 \\
\hline PS & $.17(.04)$ & $.27 *$ & $.18(.04)$ & $.27 *$ & $.18(.04)$ & $.28 *$ \\
\hline Age & $-.00(.05)$ & -.00 & $-.00(.05)$ & -.01 & $-.01(.05)$ & -.01 \\
\hline MACHxPS & & & $.08(.04)$ & $.14 *$ & $.08(.04)$ & $.14 *$ \\
\hline MACHxAge & & & $.00(.04)$ & -.00 & $.00(.04)$ & .00 \\
\hline PSxAge & & & $.08(.04)$ & $.13^{*}$ & $.08(.04)$ & $.13 *$ \\
\hline MACHxPSxAge & & & & & $.02(.04)$ & .04 \\
\hline$R^{2}$ & & $.088^{*}$ & & $.120^{*}$ & & $.121 *$ \\
\hline$F_{R^{2}}(d f 1, d f 2)$ & & 246) & & , 243) & & $4.18(8,242)$ \\
\hline$\Delta R^{2}$ & & & & $.032 *$ & & .001 \\
\hline$F_{\Delta R^{2}}(d f 1, d f 2)$ & & & & 243) & & $0.22(1,242)$ \\
\hline
\end{tabular}

Note. $N=251$; Tenure $=$ job tenure in years, $\mathrm{MACH}=$ Machiavellianism, $\mathrm{PS}=$ political skill. $* p<.05$. 


\section{Analyses in Study 2 without Control Variable (Table 3a) and Age and Tenure reversed (Table 3b)}

Appendix Table 3a

Hierarchical Moderated Regression Analysis for Counterproductive Work Behavior Directed Against the Organization and Interpersonally-Directed Counterproductive Work Behavior in Sample 2

\begin{tabular}{|c|c|c|c|c|c|c|c|c|c|c|c|c|}
\hline \multirow[b]{3}{*}{ Predictors } & \multicolumn{6}{|c|}{ CWB-I } & \multicolumn{6}{|c|}{ CWB-O } \\
\hline & \multicolumn{2}{|c|}{ Model 2a } & \multicolumn{2}{|c|}{ Model 2b } & \multicolumn{2}{|c|}{ Model 2c } & \multicolumn{2}{|c|}{ Model 3a } & \multicolumn{2}{|c|}{ Model 3b } & \multicolumn{2}{|c|}{ Model 3c } \\
\hline & $\beta$ & $B(S E)$ & $\beta$ & $B(S E)$ & $\beta$ & $B(S E)$ & $\beta$ & $B(S E)$ & $\beta$ & $B(S E)$ & $\beta$ & $B(S E)$ \\
\hline $\mathrm{MACH}$ & $.39 *$ & $.33(.03)$ & $.37 *$ & $.31(.03)$ & $.36^{*}$ & $.31(.03)$ & $.31 *$ & $.23(.03)$ & $.31 *$ & $.23(.03)$ & $.31 *$ & $.23(.03)$ \\
\hline PS & $-.17 *$ & $-.15(.03)$ & $-.21^{*}$ & $-.18(.04)$ & $-.19 *$ & $-.17(.04)$ & $-.14^{*}$ & $-.11(.03)$ & $-.19 *$ & $-.14(.03)$ & $-.17 *$ & $-.13(.03)$ \\
\hline Tenure & -.01 & $.00(.03)$ & .03 & $.02(.05)$ & $.15^{*}$ & $.03(.05)$ & $-.11^{*}$ & $-.09(.03)$ & -.10 & $.08(.05)$ & -.09 & $.07(.05)$ \\
\hline MACHxMACH & & & $.11^{*}$ & $.06(.02)$ & $.11 *$ & $.07(.02)$ & & & .01 & $.00(.02)$ & .02 & $.01(.02)$ \\
\hline PSxPS & & & -.03 & $-.01(.02)$ & -.01 & $-.01(.02)$ & & & -.03 & $-.02(.02)$ & -.02 & $-.01(.02)$ \\
\hline TenurexTenure & & & -.06 & $-.03(.03)$ & -.09 & $-.03(.03)$ & & & -.04 & $-.02(.02)$ & -.03 & $-.03(.02)$ \\
\hline MACHxPS & & & $-.10 *$ & $-.08(.03)$ & $-.11 *$ & $-.08(.03)$ & & & $-.10 *$ & $-.07(.03)$ & $-.11 *$ & $-.07(03)$ \\
\hline MACHxTenure & & & -.00 & $.00(.03)$ & .01 & $.00(.03)$ & & & -.04 & $-.03(.03)$ & -.03 & $-.02(.03)$ \\
\hline PSxTenure & & & -.02 & $-.02(.04)$ & .06 & $.05(.04)$ & & & .03 & $.02(.03)$ & $.11^{*}$ & $.09(.04)$ \\
\hline MACHxMACHxPS & & & .08 & $.03(.02)$ & .02 & $.01(.02)$ & & & .08 & $.03(.02)$ & .02 & $.01(.02)$ \\
\hline MACHxMACHxTenure & & & .02 & $-.01(.03)$ & -.00 & $-.00(.03)$ & & & .02 & $.01(.02)$ & .00 & $.00(.02)$ \\
\hline MACHxPSxTenure & & & & & .02 & $.02(.03)$ & & & & & .02 & $.02(.03)$ \\
\hline MACHxMACHxPSxTenure & & & & & $-.16^{*}$ & $-.07(.02)$ & & & & & $-.17 *$ & $-.07(.02)$ \\
\hline$R^{2}$ & & $.181^{*}$ & & $.202 *$ & & $.214^{*}$ & & $.137^{*}$ & & $.151^{*}$ & & $.164^{*}$ \\
\hline$F_{R^{2}}(d f 1, d f 2)$ & & $06(3,681)$ & 15.5 & $1(11,673)$ & 14. & $7(13,671)$ & & $04(3,681)$ & 10.8 & $4(11,673)$ & 10.1 & $4(13,671)$ \\
\hline & & & & $.022 *$ & & $.012 *$ & & & & .014 & & $.014^{*}$ \\
\hline$F_{\Delta R^{2}}(d f 1, d f 2)$ & & & & $28(8,673)$ & & $10(2,671)$ & & & & $36(8,672)$ & & $45(2,671)$ \\
\hline
\end{tabular}

Note. $N=685$; Tenure = job tenure in years, CWB-I = Interpersonally-directed counterproductive work behavior, $\mathrm{CWB}-\mathrm{O}=\mathrm{Counterproductive} \mathrm{work} \mathrm{behavior} \mathrm{directed}$ towards the organization, $\mathrm{MACH}=$ Machiavellianism, $\mathrm{PS}=$ Political skill.

$* p<.05$. 
Appendix Table $3 b$

Hierarchical Moderated Regression Analysis for Counterproductive Work Behavior Directed Against the Organization and Interpersonally-Directed Counterproductive Work Behavior in Sample 2

\begin{tabular}{|c|c|c|c|c|c|c|c|c|c|c|c|c|}
\hline \multirow[b]{3}{*}{ Predictors } & \multicolumn{6}{|c|}{ CWB-I } & \multicolumn{6}{|c|}{ CWB-O } \\
\hline & \multicolumn{2}{|c|}{ Model 2a } & \multicolumn{2}{|c|}{ Model 2b } & \multicolumn{2}{|c|}{ Model 2c } & \multicolumn{2}{|c|}{ Model 3a } & \multicolumn{2}{|c|}{ Model 3b } & \multicolumn{2}{|c|}{ Model 3c } \\
\hline & $\beta$ & $B(S E)$ & $\beta$ & $B(S E)$ & $\beta$ & $B(S E)$ & $\beta$ & $B(S E)$ & $\beta$ & $B(S E)$ & $\beta$ & $B(S E)$ \\
\hline Tenure & .07 & $.06(.04)$ & .07 & $.06(.04)$ & .07 & $.06(.04)$ & -.01 & $-.01(.03)$ & -.01 & $-.01(.03)$ & -.01 & $-.01(.03)$ \\
\hline $\mathrm{MACH}$ & $.38 *$ & $.32(.03)$ & $.34 *$ & $.29(.03)$ & $.34 *$ & $.29(.03)$ & $.29^{*}$ & $.21(.03)$ & $.29^{*}$ & $.22(.03)$ & $.29^{*}$ & $.21(.03)$ \\
\hline PS & $-.17 *$ & $-.14(.03)$ & $-.19 *$ & $-.16(.04)$ & $-.19 *$ & $-.16(.04)$ & $-.14^{*}$ & $-.10(.03)$ & $-.17 *$ & $-.13(.03)$ & $-.17^{*}$ & $-.13(.03)$ \\
\hline Age & $-.13 *$ & $-.11(.04)$ & -.09 & $-.08(.04)$ & -.09 & $-.08(.04)$ & $-.17 *$ & $-.13(.03)$ & $-.16^{*}$ & $-.12(.04)$ & $-.16^{*}$ & $-.12(.04)$ \\
\hline MACHxMACH & & & $.09 *$ & $.05(.02)$ & $.09 *$ & $.05(.02)$ & & & -.01 & $-.00(.02)$ & -.00 & $.00(.02)$ \\
\hline PSxPS & & & -.02 & $-.01(.02)$ & -.03 & $-.02(.02$ & & & -.02 & $-.01(.02)$ & -.04 & $-.02(.02)$ \\
\hline AgexAge & & & -.04 & $-.05(.03)$ & -.05 & $-.05(.04)$ & & & $-.10^{*}$ & $-.10(.04)$ & $-.10^{*}$ & $-.10(.04)$ \\
\hline MACHxPS & & & $-.09 *$ & $-.07(.03)$ & $-.10^{*}$ & $-.08(.03)$ & & & $-.09 *$ & $-.06(.03)$ & $-.10 *$ & $-.07(.03)$ \\
\hline MACHxAge & & & -.06 & $-.05(.03)$ & -.06 & $-.05(.03)$ & & & -.06 & $-.05(.03)$ & -.06 & $-.05(.03)$ \\
\hline PSxAge & & & .04 & $.03(.03)$ & .06 & $.05(.04)$ & & & .07 & $.05(.03)$ & $.10^{*}$ & $.08(.03)$ \\
\hline MACHxMACHxPS & & & .04 & $.02(.02)$ & .07 & $.03(.02)$ & & & .05 & $.02(.02)$ & .08 & $.03(.02)$ \\
\hline MACHxMACHxAge & & & -.05 & $-.02(.02)$ & -.04 & $-.02(.02)$ & & & .01 & $.01(.02)$ & .02 & $.01(.02)$ \\
\hline MACHxPSxAge & & & & & .08 & $.06(.03)$ & & & & & $.10^{*}$ & $.06(.03)$ \\
\hline MACHxMACHxPSxAge & & & & & -.06 & $-.02(.02)$ & & & & & -.08 & $-.03(.02)$ \\
\hline$R^{2}$ & & $.190^{*}$ & & $.217^{*}$ & & $.221 *$ & & $.154 *$ & & $.180^{*}$ & & $.187^{*}$ \\
\hline$F_{R^{2}}(d f 1, d f 2)$ & & $8(4,680)$ & 15.5 & $4(12,672)$ & 13.6 & $2(14,670)$ & & $90(4,680)$ & 12.2 & $9(12,672)$ & 10.9 & $(14,670)$ \\
\hline$\Delta R^{2}$ & & & & $.027 *$ & & .004 & & & & $.026^{*}$ & & .007 \\
\hline$F_{\Delta R^{2}}(d f 1, d f 2)$ & & & & $88(8,672)$ & & $34(2,670)$ & & & & $68(8,672)$ & & $9(2,670)$ \\
\hline
\end{tabular}

Note. $N=685$; Tenure = job tenure in years, $\mathrm{CWB}-\mathrm{I}=$ Interpersonally-directed counterproductive work behavior, $\mathrm{CWB}-\mathrm{O}=\mathrm{Counterproductive} \mathrm{work} \mathrm{behavior} \mathrm{directed}$ towards the organization, $\mathrm{MACH}=$ Machiavellianism, PS $=$ Political skill. $* p<.05$. 


\section{Four-way (Table 4a) and quadratic four-way interactions (Table $4 b$ and 4c) of MACH, PS, Tenure and Age in Sample 1 and Sample 2}

Table 4a

Hierarchical Moderated Regression Analysis for Career Role Performance in Sample 1

\begin{tabular}{|c|c|c|c|c|c|c|}
\hline & \multicolumn{2}{|c|}{ Model 1a } & \multicolumn{2}{|c|}{ Model 1b } & \multicolumn{2}{|c|}{ Model 1c } \\
\hline Predictors & $B(S E)$ & $\beta$ & $B(S E)$ & $\beta$ & $B(S E)$ & $\beta$ \\
\hline Tenure & $-.06(.05)$ & -.09 & $-.05(.06)$ & -.08 & $-.06(.07)$ & -.09 \\
\hline MACH & $-.06(.04)$ & -.10 & $-.03(.04)$ & -.04 & $-.03(.04)$ & -.04 \\
\hline PS & $.17(.04)$ & $.27 *$ & $.15(.06)$ & $.24 *$ & $.15(.06)$ & $.24 *$ \\
\hline Age & $-.00(.05)$ & -.00 & $-.01(.06)$ & -.01 & $-.00(.06)$ & -.01 \\
\hline MACHxPS & & & $.09(.04)$ & $.16^{*}$ & $.13(.05)$ & $.22 *$ \\
\hline MACHxAge & & & $.05(.05)$ & .07 & $.04(.05)$ & .07 \\
\hline MACHxTenure & & & $-.06(.05)$ & -.08 & $-.05(.05)$ & -.07 \\
\hline PSxAge & & & $.11(.06)$ & .17 & $.11(.06)$ & .18 \\
\hline PSxTenure & & & $-.06(.07)$ & -.09 & $-.07(.07)$ & -.09 \\
\hline TenurexAge & & & $-.00(.06)$ & -.00 & $.01(.06)$ & .01 \\
\hline MACHxPSxAge & & & $-.08(.06)$ & -.13 & $-.13(.08)$ & -.21 \\
\hline MACHxPSxTenure & & & $.16(.06)$ & $.24 *$ & $.18(.06)$ & $.27^{*}$ \\
\hline PSxAgexTenure & & & $.00(.06)$ & .00 & $-.00(.06)$ & -.01 \\
\hline MACHxPSxTenurexAge & & & & & $-.08(.08)$ & -.12 \\
\hline$R^{2}$ & & $.088^{*}$ & & $.155^{*}$ & & $.159^{*}$ \\
\hline$F_{R^{2}}(d f 1, d f 2)$ & & ,246) & & ,237) & & $.19(14,236)$ \\
\hline$\Delta R^{2}$ & & & & $.067^{*}$ & & .004 \\
\hline$F_{\Delta R^{2}}(d f 1, d f 2)$ & & & & ,237) & & $1.02(1,236)$ \\
\hline
\end{tabular}

Note. $N=251$; Tenure $=$ job tenure in years, $\mathrm{MACH}=$ Machiavellianism, $\mathrm{PS}=$ political skill. $* p<.05$. 
Table 4b

Hierarchical Moderated Regression Analysis for Counterproductive Work Behavior Interpersonally-Directed Counterproductive Work Behavior in Sample 2

\begin{tabular}{|c|c|c|c|c|c|c|}
\hline \multirow[b]{3}{*}{ Predictors } & \multicolumn{6}{|c|}{ CWB-I } \\
\hline & \multicolumn{2}{|c|}{ Model 2a } & \multicolumn{2}{|c|}{ Model 2b } & \multicolumn{2}{|c|}{ Model 2c } \\
\hline & $\beta$ & $B(S E)$ & $\beta$ & $B(S E)$ & $\beta$ & $B(S E)$ \\
\hline Tenure & .07 & $.06(.04)$ & .12 & $.10(.07)$ & .12 & $.10(.07)$ \\
\hline $\mathrm{MACH}$ & $.38^{*}$ & $.32(.03)$ & $.35^{*}$ & $.30(.03)$ & $.35^{*}$ & $.30(.03)$ \\
\hline PS & $-.17 *$ & $-.14(.03)$ & $-.19^{*}$ & $-.16(.05)$ & $-.18 *$ & $-.15(.05)$ \\
\hline Age & $-.13 *$ & $-.11(.04)$ & -.10 & $-.08(.06)$ & -.09 & $-.08(.06)$ \\
\hline MACHXMACH & & & $.10^{*}$ & $.06(.02)$ & $.10^{*}$ & $.06(.02)$ \\
\hline PSxPS & & & -.01 & $.00(.02)$ & .00 & $.00(.02)$ \\
\hline AgexAge & & & -.05 & $-.06(05)$ & -.05 & $-.06(.05)$ \\
\hline TenurexTenure & & & -.09 & $-.05(.04)$ & $-.10^{*}$ & $-.05(.04)$ \\
\hline MACHxPS & & & $-.18^{*}$ & $-.13(.04)$ & $-.16^{*}$ & $-.12(.04)$ \\
\hline MACHxAge & & & $-.13^{*}$ & $-.11(.04)$ & -.13 & $-.12(.04)$ \\
\hline PSxAge & & & $.13^{*}$ & $.11(.05)$ & $.12^{*}$ & $.10(.05)$ \\
\hline MACHxTenure & & & $.11^{*}$ & $.10(.04)$ & $.11^{*}$ & $.10(.04)$ \\
\hline PSxTenure & & & -.06 & $-.06(.07)$ & -.04 & $-.04(.07)$ \\
\hline TenurexAge & & & .04 & $.03(.07)$ & .04 & $.04(.08)$ \\
\hline MACHxMACHxPS & & & .01 & $.01(.02)$ & -.01 & $.00(.03)$ \\
\hline MACHxMACHxAge & & & -.08 & $-.04(.03)$ & -.08 & $-.04(.03)$ \\
\hline MACHxMACHxTenure & & & .05 & $.03(.03)$ & .06 & $.03(.03)$ \\
\hline MACHxPSxAge & & & $.14^{*}$ & $.10(.04)$ & $.13^{*}$ & $.10(.04)$ \\
\hline MACHxPSxTenure & & & -.09 & $-.07(.05)$ & -.07 & $-.06(.05)$ \\
\hline PSxTenurexAge & & & .04 & $.03(.05)$ & .01 & $.01(.06)$ \\
\hline MACHxMACHxPSxage & & & -.08 & $-.03(.02)$ & -.04 & $-.02(.03)$ \\
\hline MACHxMACHxPSxtenure & & & -.08 & $-.04(.03)$ & -.12 & $-.05(.04)$ \\
\hline MACHxPSxTenurexAge & & & .10 & $.08(.05)$ & .08 & $.07(.05)$ \\
\hline MACHxMACHxPSxTenurexAge & & & & & .06 & $.03(.04)$ \\
\hline$R^{2}$ & & $.190^{*}$ & & $.247^{*}$ & & $.247^{*}$ \\
\hline $\begin{array}{l}F_{R^{2}}(d f 1, d f 2) \\
\Delta R^{2}\end{array}$ & & $98(4,680)$ & & $\begin{array}{r}(23,661) \\
.056^{*}\end{array}$ & & $\begin{array}{r}4(24,660) \\
.001\end{array}$ \\
\hline$F_{\Delta R^{2}}(d f 1, d f 2)$ & & & & $(19,661)$ & & $50(1,660)$ \\
\hline
\end{tabular}

Note. $N=685$; Tenure = job tenure in years, CWB-I = Interpersonally-directed counterproductive work behavior, $\mathrm{CWB}-\mathrm{O}=$ Counterproductive work behavior directed towards the organization, $\mathrm{MACH}=$ Machiavellianism, PS = Political skill. $* p<.05$. 
Table $4 \mathrm{c}$

Hierarchical Moderated Regression Analysis for Counterproductive Work Behavior Directed Against the Organization in Sample 2

\begin{tabular}{|c|c|c|c|c|c|c|}
\hline \multirow[b]{3}{*}{ Predictors } & \multicolumn{6}{|c|}{ CWB-O } \\
\hline & \multicolumn{2}{|c|}{ Model 3a } & \multicolumn{2}{|c|}{ Model 3b } & \multicolumn{2}{|c|}{ Model 3c } \\
\hline & $\beta$ & $B(S E)$ & $\beta$ & $B(S E)$ & $\beta$ & $B(S E)$ \\
\hline Tenure & -.01 & $-.01(.03)$ & -.02 & $-.02(.06)$ & -.02 & $-.02(.06)$ \\
\hline $\mathrm{MACH}$ & $.29^{*}$ & $.21(.03)$ & $.30^{*}$ & $.22(.03)$ & $.30^{*}$ & $.22(.03)$ \\
\hline PS & $-.14^{*}$ & $-.10(.03)$ & $-.15^{*}$ & $-.11(.04)$ & $-.13 *$ & $-.10(.05)$ \\
\hline Age & $-.17^{*}$ & $-.13(.03)$ & -.12 & $-.09(.05)$ & -.12 & $-.09(.05)$ \\
\hline MACHxMACH & & & .01 & $.01(.02)$ & .01 & $.01(.02)$ \\
\hline PSxPS & & & -.02 & $-.01(.02)$ & -.02 & $-.01(.02)$ \\
\hline AgexAge & & & $-.15^{*}$ & $-.15(.05)$ & $-.15^{*}$ & $-.15(.05)$ \\
\hline TenurexTenure & & & -.12 & $-.05(.03)$ & -.12 & $-.05(.03)$ \\
\hline MACHxPS & & & $-.13 *$ & $-.08(.03)$ & $-.11 *$ & $-.07(.04)$ \\
\hline MACHxAge & & & -.08 & $-.06(.04)$ & -.08 & $-.06(.04)$ \\
\hline PSxAge & & & .11 & $.08(.05)$ & .09 & $.07(.05)$ \\
\hline MACHxTenure & & & .03 & $.02(.04)$ & .03 & $.02(.04)$ \\
\hline PSxTenure & & & .04 & $.03(.06)$ & .07 & $.06(.06)$ \\
\hline TenurexAge & & & .15 & $.12(.07)$ & .15 & $.12(.07)$ \\
\hline MACHxMACHxPS & & & .04 & $.01(.02)$ & -.01 & $.00(.02)$ \\
\hline MACHxMACHxAge & & & .04 & $.02(.03)$ & .03 & $.01(.03)$ \\
\hline MACHxMACHxTenure & & & -.03 & $-.01(.03)$ & -.02 & $-.01(.03)$ \\
\hline MACHxPSxAge & & & $.12 *$ & $.08(.04)$ & .11 & $.07(.04)$ \\
\hline MACHxPSxTenure & & & -.05 & $-.03(.04)$ & -.02 & $-.02(.05)$ \\
\hline PSxTenurexAge & & & -.01 & $.00(.04)$ & -.06 & $-.04(.05)$ \\
\hline MACHxMACHxPSxAge & & & -.08 & $-.02(.02)$ & -.01 & $.00(.03)$ \\
\hline MACHxMACHxPSxTenure & & & $-.12 *$ & $-.05(.02)$ & $-.19^{*}$ & $-.08(.03)$ \\
\hline MACHxPSxTenurexAge & & & .02 & $.02(.04)$ & -.01 & $-.01(.05)$ \\
\hline MACHxMACHxPSxTenurexAge & & & & & .11 & $.04(.03)$ \\
\hline$R^{2}$ & & $.154 *$ & & $.203 *$ & & $.205^{*}$ \\
\hline $\begin{array}{l}F_{R^{2}}(d f 1, d f 2) \\
\Delta R^{2}\end{array}$ & & $90(4,680)$ & & $\begin{array}{r}2(23,661) \\
.049^{*}\end{array}$ & & $\begin{array}{r}8(24,660) \\
.002\end{array}$ \\
\hline$F_{\Delta R^{2}}(d f 1, d f 2)$ & & & & $(19,661)$ & & $40(1,660)$ \\
\hline
\end{tabular}

Note. $N=685$; Tenure = job tenure in years, CWB-I = Interpersonally-directed counterproductive work behavior, $\mathrm{CWB}-\mathrm{O}=$ Counterproductive work behavior directed towards the organization, $\mathrm{MACH}=$ Machiavellianism, PS = Political skill.

$* p<.05$. 


\section{References}

Eby, L. T., Butts, M., \& Lockwood, A. (2003). Predictors of success in the era of the boundaryless career. Journal of Organizational Behavior: The International Journal of Industrial, Occupational and Organizational Psychology and Behavior, 24, 689-708.

Fay, D., \& Frese, M. (2001). The concepts of personal initiative (PI): An overview of validity studies. Human Performance, 14, 97-124.

McDonald, R. P. (1999). Test theory: A unified treatment. Mahwah, NJ: Erlbaum.

Morrison, E. W., \& Phelps, C. C. (1999). Taking charge at work: Extrarole efforts to initiate workplace change. Academy of Management Journal, 42, 403-419.

Reise, S. P. (2012). The rediscovery of bifactor measurement models. Multivariate Behavioral Research, 47, 667-696.

Schönbrodt, F. D., \& Perugini, M. (2013). At what sample size do correlations stabilize? Journal of Research in Personality, 47, 609-612.

Weng, Q., McElroy, J. C., Morrow, P. C., \& Liu, R. (2010). The relationship between career growth and organizational commitment. Journal of Vocational Behavior, 77, 391-400. 